\title{
Widening the Window of Spin-Crossover Temperatures in Bis(formazanate)iron(II) Complexes via Steric and Noncovalent Interactions
}

Francesca Milocco, Folkert de Vries, Harmke S. Siebe, Silène Engbers, Serhiy Demeshko, Franc Meyer, and Edwin Otten*

Cite This: Inorg. Chem. 2021, 60, 2045-2055

Read Online

ABSTRACT: Bis(formazanate)iron(II) complexes undergo a thermally induced $S=0$ to $S=2$ spin transition in solution. Here we present a study of how steric effects and $\pi$-stacking interactions between the triarylformazanate ligands affect the spincrossover behavior, in addition to electronic substituent effects. Moreover, the effect of increasing the denticity of the formazanate ligands is explored by including additional OMe donors in the ligand (7). In total, six new compounds (2-7) have been synthesized and characterized, both in solution and in the solid state, via spectroscopic, magnetic, and structural analyses. The series spans a broad range of spin-crossover temperatures $\left(T_{1 / 2}\right)$ for the LS $\rightleftharpoons$ HS equilibrium in solution, with the exception of

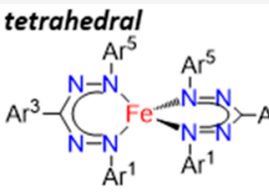
Bis(formazanate) iron(II) complexes

Ligand effects:

sterics

$\pi$-stacking

$\square$ denticity

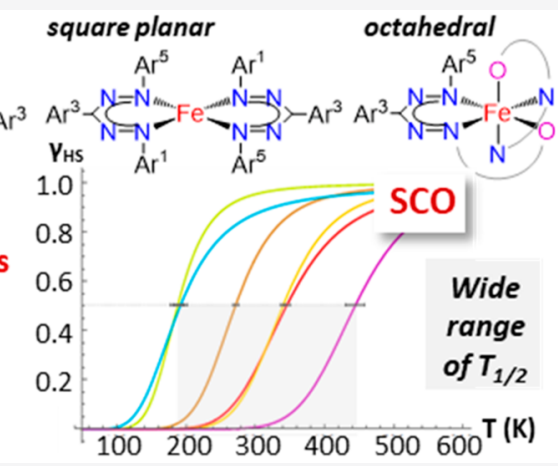
compound 6 which remains high-spin $(S=2)$ down to $210 \mathrm{~K}$. In the solid state, 6 was shown to exist in two distinct forms: a tetrahedral high-spin complex $(6 a, S=2)$ and a rare square-planar structure with an intermediate-spin state $(6 \mathbf{b}, S=1)$. SQUID measurements, ${ }^{57} \mathrm{Fe}$ Mössbauer spectroscopy, and differential scanning calorimetry indicate that in the solid state the square-planar form $\mathbf{6 b}$ undergoes an incomplete spin-change-coupled isomerization to tetrahedral 6a. The complex that contains additional OMe donors (7) results in a six-coordinate (NNO) ${ }_{2} \mathrm{Fe}$ coordination geometry, which shifts the spin-crossover to significantly higher temperatures $\left(T_{1 / 2}=444 \mathrm{~K}\right)$. The available experimental and computational data for 7 suggest that the Fe...OMe interaction is retained upon spin-crossover. Despite the difference in coordination environment, the weak OMe donors do not significantly alter the electronic structure or ligand-field splitting, and the occurrence of spin-crossover (similar to the compounds lacking the OMe groups) originates from a large degree of metal-ligand $\pi$-covalency.

\section{INTRODUCTION}

The geometry of transition metal complexes is dependent on the electronic structure, ${ }^{1}$ and it is often the case that the geometry preferred on steric grounds is overridden in favor of a different one by electronic effects. ${ }^{2}$ In four-coordinate complexes two extreme geometries can be observed: the sterically favored tetrahedral and the electronically stabilized square-planar structure. While complexes with a $\mathrm{d}^{8}$ configuration have been thoroughly investigated, the balance between steric and electronic effects on the geometry of compounds with a lower d-electron count is not well established. In the case of first-row transition metals such as $\mathrm{Fe}(\mathrm{II})$, the electronic stabilization is typically small, and therefore these compounds tend to adopt a tetrahedral configuration. ${ }^{1 a, 2,3}$ Therefore, to observe square-planar Fe(II) complexes, specific requirements are usually needed that result in intermediate-spin $(S=1)$ compounds: ${ }^{1 \mathrm{~b}}$ (i) macrocyclic ligands that enforce a planar geometry around the metal center $^{4}$ or (ii) strong field ligands, e.g., phosphines, that provide a greater ligand field stabilization energy compared to nitrogen and oxygen donors (in the case of mono- and bidentate ligands), often in combination with ortho-substituted aryl coligands. ${ }^{1 \mathrm{~b}, 5}$ Exceptions to this where $\mathrm{Fe}(\mathrm{II})$ squareplanar structures were observed have been sporadically reported. ${ }^{6}$ Furthermore, while isomerization between tetrahedral and square-planar geometries is a well-established phenomenon for cobalt(II), ${ }^{7}$ nickel(II),$^{7 \mathrm{a}}$ and copper(II), ${ }^{7 \mathrm{a}, 8}$ it is rare for iron(II). ${ }^{6 e}$

In the simplistic terms of crystal field theory, the spin state of a complex in a certain geometry is determined by the orbital splitting $(\Delta)$ and the pairing energy $(\mathrm{PE}) .{ }^{1 \mathrm{a}}$ When the values of these two parameters are comparable, various electronic

Received: December 9, 2020

Published: January 19, 2021 
configurations, differing in the spin state, may be accessible. This opens the possibility of switching between different spin states by using external stimuli (e.g., temperature, pressure, or light), leading to the phenomenon of spin-crossover (SCO). ${ }^{9}$ While the major representatives in the category of spincrossover compounds are six-coordinate $\mathrm{Fe}$ (II) complexes with nitrogen donor ligands, ${ }^{9 c, 10}$ pioneering work on fourcoordinate $\mathrm{Fe}$ (II) compounds has been conducted by the groups of Chirik, ${ }^{11}$ Smith, ${ }^{12}$ Peters, ${ }^{13}$ and ours. ${ }^{14}$ To illustrate the relationship between geometry and spin state in $\mathrm{Fe}$ (II) complexes, a comparison of the expected splitting of the dorbital manifold in common coordination geometries is provided in Figure $1 \mathrm{~A}-\mathrm{C}$. The role of ligand design in tuning

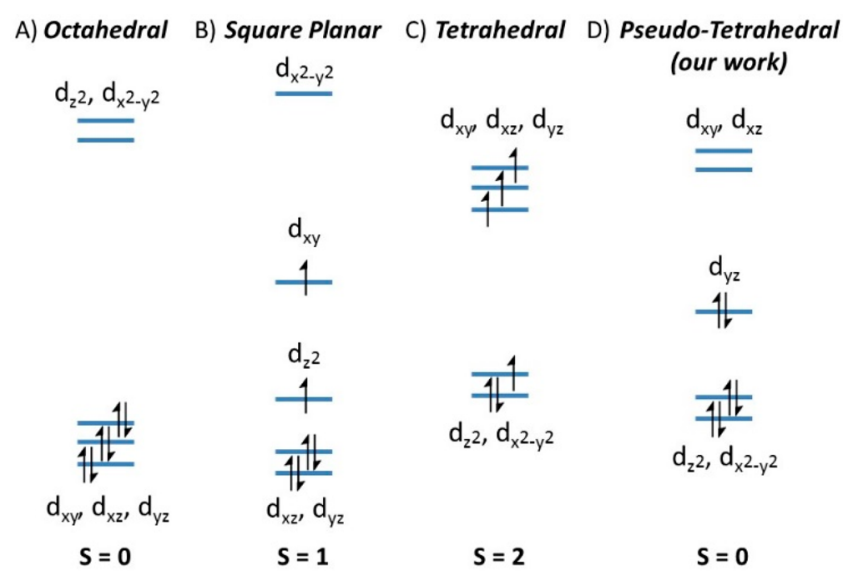

Figure 1. Common ligand field splitting diagrams for octahedral (A), square-planar (B), and tetrahedral (C) geometries and unusual ligand field splitting for the pseudo-tetrahedral geometries found in bis(formazanate)iron(II) complexes (D). ${ }^{14}$

the SCO properties, such as the spin-crossover temperature $\left(T_{1 / 2}\right)$, is well recognized. ${ }^{15}$ However, predicting the effect of changes in steric/electronic properties of the ligand and spincrossover energetics remains very challenging due to the small energy differences involved.

Following our report of a four-coordinate $\mathrm{Fe}(\mathrm{II})$ spincrossover complex with formazanate ligands, ${ }^{14 a}$ we recently established that spin-crossover is a general feature of this class of compounds. ${ }^{14 \mathrm{~b}}$ The stability of the low-spin $(S=0)$ state for these compounds is ascribed to an unusual splitting pattern of the d-orbitals in this geometry. Specifically, the formazanate ligands, which are good $\pi$-acceptor ligands, are engaged in $\pi$ - backdonation with the metal, and this allows the formation of a highly covalent metal-ligand bond, stabilizing one of the $d$ orbitals (the antibonding $d_{y z}$ orbital that belongs to the $t_{2}$ set in a conventional tetrahedral complex), which gives rise to an "inverted" ligand field with an approximate "two-over-three" splitting pattern (Figure 1D). We demonstrated that it is possible to tune the SCO properties of bis(formazanate)iron(II) complexes by substituent effects that are purely electronic in nature. ${ }^{14 \mathrm{~b}}$ In the present work, we extend these studies to include steric effects as well as $\pi$-stacking interactions between the triarylformazanate ligands. Included in this analysis are nonsymmetric ligands that have two different $\mathrm{N}-\mathrm{Ar}$ substituents. In addition, we describe the effect of additional OMe donor groups in the ligand. The aim of this work is to obtain comprehensive insight into how the spin-crossover properties of this class of compounds may be modulated via modification of the ligand.

\section{RESULTS AND DISCUSSION}

The bis(formazanate) iron complexes 2-7 were synthesized following a procedure previously reported by us ${ }^{14 \mathrm{~b}}$ starting from the iron precursor $\mathrm{Fe}\left[\mathrm{N}\left(\mathrm{SiMe}_{3}\right)_{2}\right]_{2}$ as depicted in Scheme 1. Complex $\mathbf{1}$ has already been extensively studied in our previous work, ${ }^{14 a}$ and it is therefore included in the discussion as reference compound. Besides compounds $\mathbf{1}$ and 2 , all the others feature nonsymmetric ligands that have two different $\mathrm{N}-\mathrm{Ar}$ substituents. The effect of an electronwithdrawing perfluorinated ring $\left(\mathrm{Ar}=\mathrm{C}_{6} \mathrm{~F}_{5}\right)$ is studied either in the $\mathrm{C}-\mathrm{Ar}^{3}$ position ( 2 and 4 ), as the $\mathrm{N}-\mathrm{Ar}^{1}$ group (5), or in both positions (6). At the same time the influence of the electron-donating, sterically demanding mesityl group $\left(\mathrm{Ar}^{5}=\right.$ Mes) is investigated in the $\mathrm{N}-\mathrm{Ar}$ position either alone (3) or in combination with the perfluorinated ring $(4,5$, and 6$)$. Furthermore, the ortho-anisyl group $\left(\mathrm{Ar}^{1}=o\right.$-An $)$ is introduced in the $\mathrm{N}-\mathrm{Ar}$ position in compound 7 , increasing the coordination ability of the formazanate to a tridentate monoanionic ligand.

Solid-State Characterization. While attempts to obtain single crystals suitable for X-ray diffraction were not successful for 2 and 5 , the other compounds could be obtained in crystalline form. Single-crystal X-ray diffraction studies for complexes 3, 4, 6, and 7 allowed determination of their molecular structure, and pertinent metrical parameters are collected in Table 1. Overall, the structure of compound 3 is very similar to 1 : it has relatively short $\mathrm{Fe}-\mathrm{N}$ distances averaging to $1.831 \AA$ and a flattened tetrahedral geometry

Scheme 1. Synthesis of Compounds 1-7

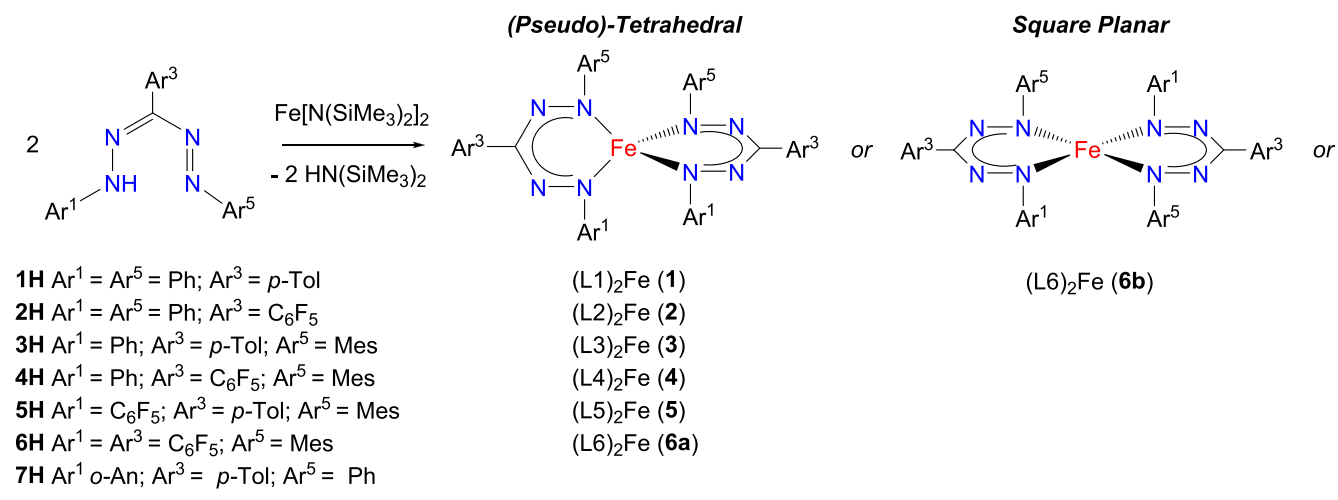

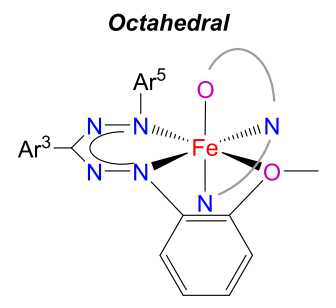

$(\mathrm{L} 7)_{2} \mathrm{Fe}(7)$ 
Table 1. Selected Bond Lengths ( $\AA$ ) and Angles (deg) in Compounds 1, 3, 4, 6, and 7 at 100 K (Unless Stated otherwise)

\begin{tabular}{|c|c|c|c|c|c|c|}
\hline & $1^{a}$ & 3 & 4 & $6 a^{b}$ & $6 b$ & 7 \\
\hline $\mathrm{Fe}(1)-\mathrm{N}(1)$ & $1.8278(15)$ & $1.8192(14)$ & $1.9946(11)$ & $2.030(2)$ & $1.9259(9)$ & $1.877(2)$ \\
\hline $\mathrm{Fe}(1)-\mathrm{N}(4)$ & $1.8207(15)$ & $1.8351(13)$ & $1.9610(12)$ & $1.9851(19)$ & $1.9461(9)$ & $1.883(2)$ \\
\hline $\mathrm{Fe}(1)-\mathrm{N}(5)$ & $1.8330(16)$ & $1.8242(13)$ & $1.9864(12)$ & $2.035(2)$ & & $1.874(2)$ \\
\hline $\mathrm{Fe}(1)-\mathrm{N}(8)$ & $1.8174(16)$ & $1.8449(13)$ & $1.9616(12)$ & $1.9966(19)$ & & $1.895(2)$ \\
\hline $\mathrm{Fe}(1)-\mathrm{O}(1)$ & & & & & & $2.1128(18)$ \\
\hline $\mathrm{Fe}(1)-\mathrm{O}(2)$ & & & & & & $2.1029(19)$ \\
\hline$\angle(\mathrm{NFeN}) /(\mathrm{NFeN})^{c}$ & $60.97(10)$ & $64.06(9)$ & $83.21(7)$ & $89.31(12)$ & $0.00(0)$ & $81.67(14)$ \\
\hline \multirow[t]{2}{*}{ Fe out-of-plane $e^{d}$} & 0.001 & 0.018 & 0.116 & 0.582 & 0.700 & 0.220 \\
\hline & 0.046 & 0.119 & 0.116 & 0.580 & & 0.224 \\
\hline
\end{tabular}

${ }^{a}$ Data taken from ref $14 a .{ }^{b}$ Structure measured at $200 \mathrm{~K}$. ${ }^{c}$ Dihedral angle between the coordination planes defined by the $\mathrm{N}-\mathrm{Fe}-\mathrm{N}$ atoms. ${ }^{d}$ Displacement of the $\mathrm{Fe}$ atom out of the plane defined by the four $\mathrm{N}$ atoms of each ligand backbone.

around the Fe center (angle between the ligand coordination planes of $\left.64.06(9)^{\circ}\right)$, features that are indicative of a low-spin $\mathrm{Fe}(\mathrm{II})$ center. $^{14 \mathrm{a}}$ The steric pressure exerted by the N-Mes groups is evinced by the $\mathrm{N}(\mathrm{Mes})-\mathrm{Fe}-\mathrm{N}(\mathrm{Mes})$ angle of $109.19(6)^{\circ}$, which is noticeably larger than the $\mathrm{N}(\mathrm{Ph})-\mathrm{Fe}-$ $\mathrm{N}(\mathrm{Ph})$ angle $\left(100.68(6)^{\circ}\right)$. The $\mathrm{N}$-mesityl rings in 3 are engaged in off-center $\pi$-stacking interactions (Figure 2) both

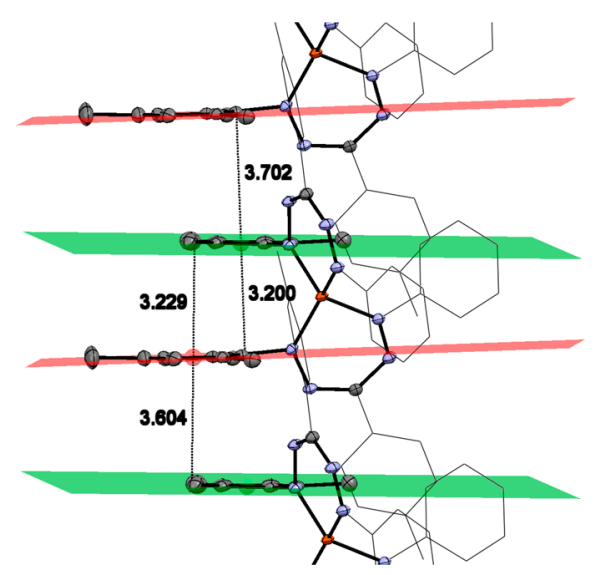

Figure 2. Crystal structure of compound 3 showing the $\pi$-stacking interactions between the mesityl rings. The $\mathrm{Fe}$ center, ligand backbone, and the mesityl rings are shown as 50\% probability ellipsoids and the remaining atoms as wireframe; hydrogen atoms are removed for clarity.

within the same molecule (interplanar angle of $2.77^{\circ}$; distance between Mes centroids and the least-squares plane of the other Mes ring of 3.200/3.229 $\AA$ ) and between neighboring molecules (centroid-to-plane distance of 3.604/3.702 $\AA$, Figure 2). Complex 4 shows similar intramolecular interactions between N-Mes groups (interplanar angle of $2.22^{\circ}$ ), but in this case the $\pi$-stacking does not extend to adjacent molecules (Figure S2). In contrast to 3 , the $\mathrm{Fe}-\mathrm{N}$ bonds are long $(1.9610(12)-1.9946(11) \AA)$, and the angle between the formazanate coordination planes is increased to $83.21(7)^{\circ}$, indicating that $\mathbf{4}$ is high-spin in the solid.

Compound 6, in which the ligands are highly asymmetric from an electronic point of view $\left(\mathrm{N}-\mathrm{C}_{6} \mathrm{~F}_{5}\right.$ and $\left.\mathrm{N}-\mathrm{Mes}\right)$, was obtained in two distinctly different forms $(\mathbf{6 a} / \mathbf{b})$ depending on the crystallization conditions. A batch of crystals was obtained from hot hexane (6a) and analyzed by single-crystal X-ray diffraction. It shows a distorted tetrahedral environment around $\mathrm{Fe}$, with off-center $\pi$-stacking between the N-Mes rings (interplanar angle of $2.87^{\circ}$ ) (Figure 3). The $\mathrm{Fe}-\mathrm{N}$
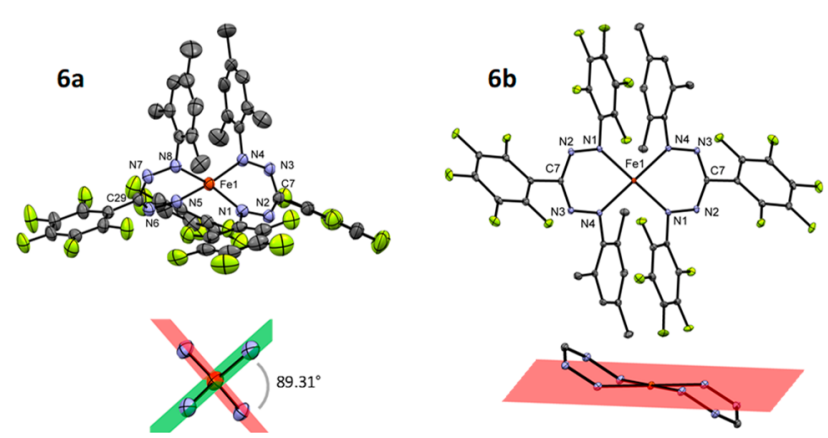

Figure 3. Molecular structure of compounds $\mathbf{6 a}$ and $\mathbf{6 b}$ showing $50 \%$ probability ellipsoids; hydrogen atoms omitted for clarity. The inset for each shows the $\mathrm{Fe}(\mathrm{NNCNN})_{2}$ core of the structure with the N$\mathrm{Fe}-\mathrm{N}$ planes and the dihedral angle.

distances of $6 \mathrm{a}(1.9851(19)-2.030(2) \AA)$ and the angle between the formazanate coordination planes $\left(89.31(12)^{\circ}\right)$ indicate a high-spin Fe center. Surprisingly, crystals obtained by diffusion of hexane into a THF solution of 6 show that under these conditions it crystallizes as a square-planar complex (6b, Figure 3).

The square-planar geometry has the $\mathrm{N}-\mathrm{Ar}$ groups in an antirelationship, which allows off-center parallel intramolecular $\pi$ stacking interactions between the electron-rich Mes and the electron-deficient $\mathrm{C}_{6} \mathrm{~F}_{5}$ groups (interplanar angle $=10.14^{\circ}$; distance $=3.259 \AA$, Figure 4). In addition, off-center parallel stacking between the $\mathrm{C}-\mathrm{C}_{6} \mathrm{~F}_{5}$ rings of neighboring molecules (centroid-to-plane distance of $3.222 \AA$ ) and a weaker intermolecular interaction between the $\mathrm{N}-\mathrm{Ar}$ groups (inter-

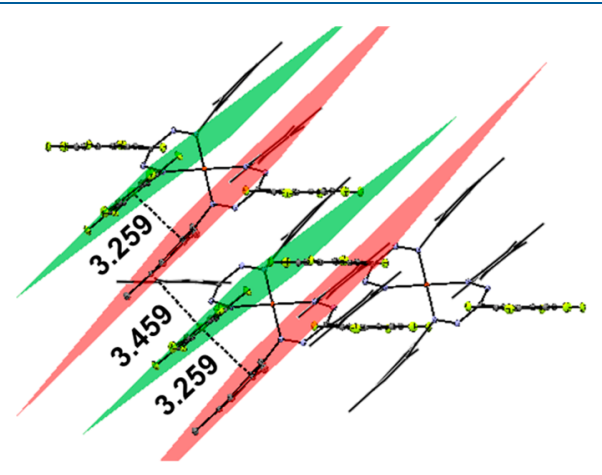

Figure 4. Crystal structure of compound $\mathbf{6 b}$ illustrating the $\pi$-stacking interactions between the aromatic rings, showing $50 \%$ probability ellipsoids. Parts of the molecule are shown as wireframe, and hydrogen atoms are removed for clarity. 
planar angle of $10.14^{\circ}$ and centroid-to-plane distance of 3.459 $\AA$ ) are observed. ${ }^{16}$ While the $\mathrm{FeN}_{4}$ fragment is planar (enforced by the crystallographic symmetry), the FeNNCNN six-membered chelate rings are puckered with the $\mathrm{Fe}$ center displaced out of the ligand plane. The $\mathrm{Fe}-\mathrm{N}$ bonds in squareplanar 6b $(1.9259(9)-1.9461(9) \AA)$ are shorter than those found in high-spin $\mathrm{FeN}_{4}$ complexes, such as tetrahedral 6a and in distorted-planar iron bis(amidinate) complexes reported by Hessen et al. $(2.0528-2.0697 \AA){ }^{6 a}$ The similarity of the metrical parameters in $\mathbf{6 b}$ to those in intermediate-spin $\mathrm{Fe}(\mathrm{II})$ porphyrins (e.g., 1.972(4) $\AA$ in $\mathrm{Fe}(\mathrm{TPP})^{4 \mathrm{a}}$ ) suggests that $\mathbf{6 b}$ also has an $S=1$ ground state. To the best of our knowledge, this is the first example of an intermediate-spin Fe(II) complex with bidentate nitrogen donor ligands which adopts a squareplanar geometry in the solid state. Although solution studies (vide infra) indicate that 6 is high-spin in toluene, the accessibility of a square-planar polymorph for $\mathbf{6}$ suggests that controlling the strength of $\pi$-stacking interactions is a viable approach to change the geometric preference and thus spin state in this class of compounds.

${ }^{57} \mathrm{Fe}$ Mössbauer spectroscopy was employed to elucidate the electronic structure of 6 . A quadrupole doublet with isomer shift $\delta=0.75 \mathrm{~mm} / \mathrm{s}$ and quadrupole splitting $\left|\Delta E_{\mathrm{q}}\right|=1.21$ $\mathrm{mm} / \mathrm{s}$ was observed for a batch of crystals for the tetrahedral complex 6a (Figure $5 \mathrm{~B}$ ). In contrast, crystals of square-planar

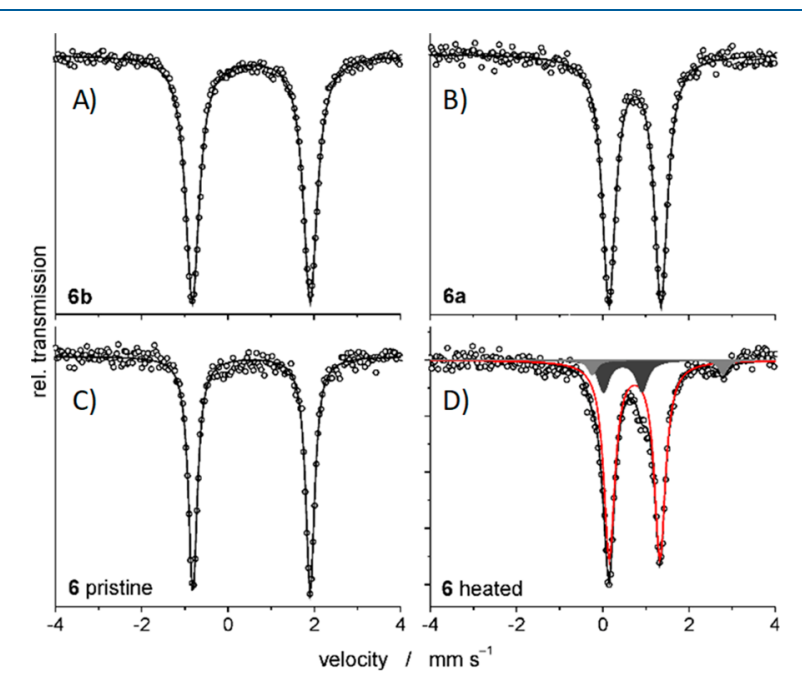

Figure 5. ${ }^{57} \mathrm{Fe}$ Mössbauer spectra at $80 \mathrm{~K}$ in the solid state of $\mathbf{6 b}(\mathrm{A})$, 6a (B), and a powder sample of 6 before (C) and after (D) heating to $400 \mathrm{~K}$ for SQUID measurements. The red line in the spectrum of heated 6 represents the main species with $82 \%$ area, and the gray subspectra are unknown impurities.

6b have a lower isomer shift $(\delta=0.54 \mathrm{~mm} / \mathrm{s})$ and a higher quadrupole splitting $\left(\left|\Delta E_{\mathrm{q}}\right|=2.73 \mathrm{~mm} / \mathrm{s}\right.$ ) (Figure $5 \mathrm{~A}$ ). The Mössbauer spectra of both batches differ significantly from low-spin $(S=0)$ bis(formazanate)iron compounds, which have isomer shifts $(\delta)$ around $0 \mathrm{~mm} / \mathrm{s}$ and an $\left|\Delta E_{\mathrm{q}}\right|$ of ca. $2 \mathrm{~mm} / \mathrm{s}^{14}$ The isomer shift of $\mathbf{6 a}$ is indicative of a high-spin state $(S=$ $2)^{17}$ and indeed is comparable to that in the high-spin bis(formazanate)iron complex $\mathrm{Fe}(\mathrm{PhNNCPhNNPh})(\delta=0.60$ $\mathrm{mm} / \mathrm{s}){ }^{14 \mathrm{~b}}$ On the other hand, the isomer shift for $\mathbf{6 b}$ is in agreement with an intermediate spin state $(S=1)$, similar to the one reported for $\mathrm{Fe}(\mathrm{TPP})(\delta=0.50 \mathrm{~mm} / \mathrm{s}) .{ }^{4 a}$ A crude powder of a pristine sample of 6 (i.e., not purified by crystallization) shows a Mössbauer spectrum identical with that of $6 \mathbf{b}$ and remains unchanged between 7 and $300 \mathrm{~K}$
(Figure 5C and Figure S4a-c). The magnetic susceptibility measurement of the powder sample of 6 recorded on a SQUID magnetometer gave $\chi_{\mathrm{M}} T \approx 1.1 \mathrm{~cm}^{3} \mathrm{~mol}^{-1} \mathrm{~K}$, supporting the assignment of an intermediate-spin state (Figure 6). The

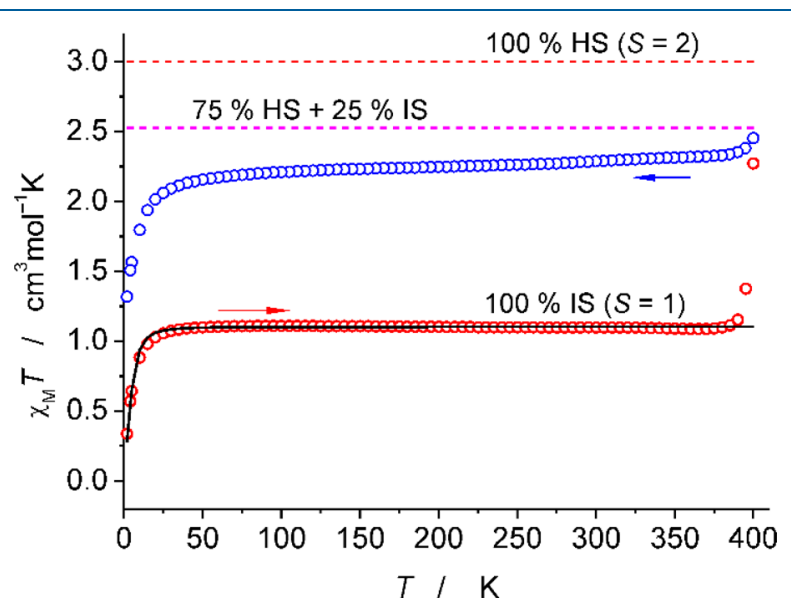

Figure 6. Magnetic susceptibility data for a powder sample of $\mathbf{6}$ in the solid state (heating to $400 \mathrm{~K}$ and subsequent cooling). The solid black line shows the best fit curve for $S=1$ with the parameters $g=2.10$ and $D=11.2 \mathrm{~cm}^{-1}$ (100\% IS). The dashed red line shows the spin-only value for an $S=2$ system.

magnetic susceptibility in the solid state stays constant up to $390 \mathrm{~K}$, and then it suddenly increases, approaching a value of $2.5 \mathrm{~cm}^{3} \mathrm{~mol}^{-1} \mathrm{~K}$ at $400 \mathrm{~K}$, which is lower than the expected value for a high-spin state $S=2$ but could be an indication of an incomplete spin transition. To further probe this, the sample used for the SQUID measurement was subsequently analyzed by Mössbauer spectroscopy (Figure 5D). After $\mathbf{6 b}$ was heated to $400 \mathrm{~K}$, the major species $(82 \%)$ has a quadrupole doublet with $\delta=0.74 \mathrm{~mm} / \mathrm{s}$ and $\left|\Delta E_{\mathrm{q}}\right|=1.17$ $\mathrm{mm} / \mathrm{s}$, which are in good agreement with the values obtained for 6a. Thus, this indicates that square-planar, intermediatespin $\mathbf{6 b}$ switches at least partially to tetrahedral, high-spin $\mathbf{6 a}$ in the solid state. Differential scanning calorimetry analysis of a fresh powder sample of 6 shows an endothermic transition at $412 \mathrm{~K}$ with an onset temperature around $397 \mathrm{~K}$ (followed by subsequent decomposition) and corroborates a spin transition in the solid state at high temperature.

Lastly, compound 7 containing formazanate ligands with an additional OMe donor moiety was characterized. Single-crystal X-ray diffraction allowed determination of the molecular structure as shown in Figure 7. It shows a distorted octahedral geometry where both the formazanate moieties act as

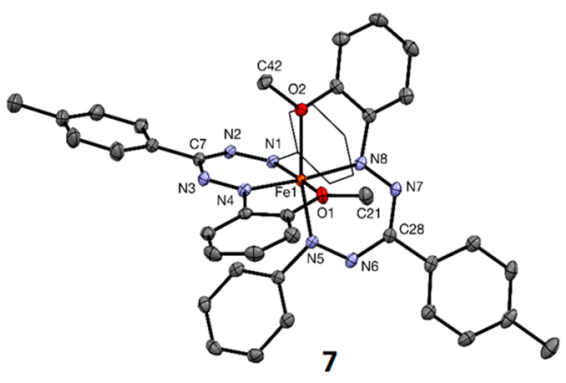

Figure 7. Molecular structures of 7 showing $50 \%$ probability ellipsoids. One of the $\mathrm{N}-\mathrm{Ph}$ rings is shown as wireframe, and hydrogen atoms are omitted for clarity. 
tridentate ligands. The $\mathrm{Fe}-\mathrm{N}$ bond lengths, which average $1.882 \AA$, are shorter than those reported for an octahedral monoformazanate iron(II) cationic complex $(\mathrm{Fe}-\mathrm{N}$ average of $1.974 \AA),{ }^{18}$ which reflects the relatively poor donor ability of the OMe groups. Nevertheless, the $\mathrm{Fe}-\mathrm{O}$ bonds in 7 are relatively short $(2.1128(18)$ and $2.1029(19) \AA$ ) and in agreement with it having a low-spin ground state. These metrical parameters stand in marked contrast to those reported by Hannedouche for an iron complex with related $\beta$ diketiminate ligands, which interact with only one $o$-OMe group $(\mathrm{Fe}-\mathrm{O}$ distance $=2.465 \AA$ ) to form a five-coordinate complex that has a high-spin ground state based on the metrical data. ${ }^{19}$

Table 2. ${ }^{57} \mathrm{Fe}$ Mössbauer Parameters $(\delta=$ Isomer Shift in $\mathrm{mm} \mathrm{s}^{-1} ;\left|\Delta E_{\mathrm{q}}\right|=$ Quadrupole Splitting in $\left.\mathrm{mm} \mathrm{s}^{-1}\right)$ for Compounds 1,3 , and $6^{a}$

$\begin{array}{lccccc} & \mathbf{1} & \mathbf{3} & \mathbf{6 a} & \mathbf{6 b} & \mathbf{6}^{b} \\ \delta & 0.03 & 0.05 & 0.75 & 0.54 & 0.55 \\ \left|\Delta E_{\mathrm{q}}\right| & 2.05 & 1.99 & 1.21 & 2.73 & 2.72\end{array}$

${ }^{a}$ Measured in the solid state at $80 \mathrm{~K} .{ }^{b}$ Powder sample of the crude product before crystallization.

Variable-Temperature NMR and UV/Vis Spectroscopy in Solution. We subsequently studied the spin-crossover behavior in solution by monitoring the spectral changes as a function of temperature. The NMR chemical shifts for all compounds are found to be temperature dependent but at low temperature do not follow the Curie behavior that is expected for a paramagnet: instead, the NMR resonances of all compounds except 6 converge into the diamagnetic range of the spectrum, suggestive of population of the $S=0$ state. With 1 as reference, the changes induced by the different ligand substituents are discussed below. The enthalpy and entropy differences $(\Delta H / \Delta S)$ that describe the LS $\rightleftharpoons$ HS equilibrium as well as the spin-crossover temperature $\left(T_{1 / 2}\right)$ for the series of compounds are collected in Table 3 , and a plot of the highspin fraction as a function of temperature is shown in Figure 8.

For compound 2, which has a symmetrical ligand with a highly electron-withdrawing $\mathrm{C}-\mathrm{Ar}^{3}$ group, the variabletemperature ${ }^{1} \mathrm{H}$ and ${ }^{19} \mathrm{~F}$ NMR spectra in toluene- $d_{8}$ are indicative of an equilibrium between the high- and low-spin states. Although the former is predominant even at $207 \mathrm{~K}$ (the lowest temperature that could be reached inside the NMR probe), and fitting the temperature dependence of the chemical shifts thus is somewhat less accurate, it is clear from the data that the thermodynamic values that describe the spin equilibrium are much decreased in $2(\Delta H=8.5 \pm 0.4 \mathrm{~kJ}$ $\left.\mathrm{mol}^{-1}, \Delta S=45 \pm 4 \mathrm{~J} \mathrm{~mol}^{-1} \mathrm{~K}^{-1}\right)$ compared to 1 . This can be attributed to the decrease in $\sigma$-donor strength of the ligands,

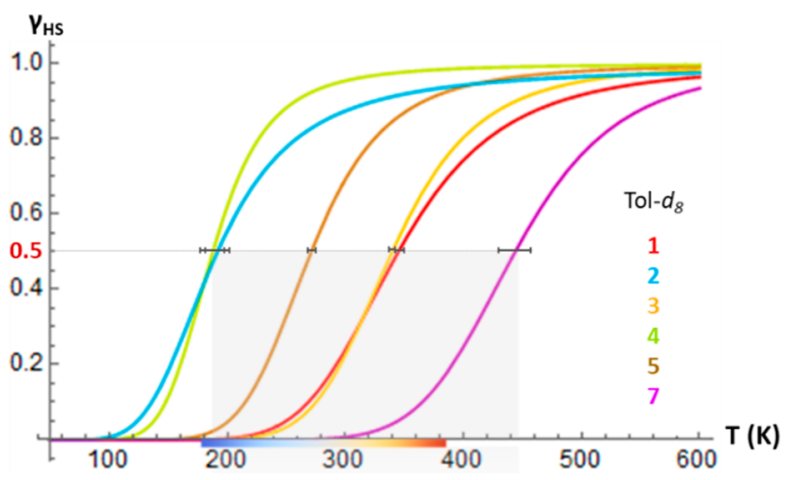

Figure 8. Temperature dependence of the high-spin fraction $\left(\gamma_{\mathrm{HS}}\right)$ of compounds $1-5$ and 7 in toluene- $d_{8}$, including error bars for $T_{1 / 2}$ $\left(\gamma_{\mathrm{HS}}=0.5\right)$. The liquid range for toluene is indicated with the color gradient at the temperature axis.

which results in a smaller ligand-field splitting and destabilization of the low-spin state.

The introduction of an electron-rich, sterically demanding mesityl ring as an $\mathrm{N}-\mathrm{Ar}$ group in compound 3 resulted in larger differences between both spin states, with $\Delta H=26.3 \pm$ $0.1 \mathrm{~kJ} \mathrm{~mol}^{-1}$ and $\Delta S=78 \pm 1 \mathrm{~J} \mathrm{~mol}^{-1} \mathrm{~K}^{-1}$ from fitting the NMR data. The increase in these values stands in contrast to the expected effect of electron-donating substituents at that position, since the $\mathrm{N}-\mathrm{Ar}$ groups predominantly influence metal-ligand $\pi$-bonding. ${ }^{14 \mathrm{~b}}$ However, it is clear from the crystallographic data of 3 (vide supra) that the $\mathrm{N}-\mathrm{Mes}$ rings are engaged in noncovalent interactions (stacking), and we conclude that these attractive forces act to stabilize the more compact low-spin state.

The two effects discussed above were subsequently combined in compound 4. While the crystallographic data indicate that $\mathbf{4}$ is high spin in the solid state, the solution data clearly indicate that the $S=0$ state is populated at low temperature. The combination of two opposing effects on the relative stability of the low-spin state results in thermodynamic parameters for the spin-state equilibrium in $4(\Delta H=12.6 \pm$ $1.0 \mathrm{~kJ} \mathrm{~mol}^{-1} ; \Delta S=67 \pm 5 \mathrm{~J} \mathrm{~mol}^{-1} \mathrm{~K}^{-1}$ ) that are intermediate between those of compounds 2 and 3 .

Subsequently, we evaluated the influence of a highly electron-withdrawing $\mathrm{N}-\mathrm{C}_{6} \mathrm{~F}_{5}$ substituent that is present in compounds 5 and $\mathbf{6}$. Changing the $\mathrm{N}-\mathrm{Ph}$ group in 3 to $\mathrm{N}-$ $\mathrm{C}_{6} \mathrm{~F}_{5}$ in 5 results in a noticeable decrease in $\Delta H$ and $\Delta S$ to values of $19.0 \pm 0.4 \mathrm{~kJ} \mathrm{~mol}^{-1}$ and $70 \pm 1 \mathrm{~J} \mathrm{~mol}^{-1} \mathrm{~K}^{-1}$, respectively. In the absence of structural data for $\mathbf{5}$, we refrain from a detailed interpretation of these values. It is noted, however, that this result runs counter to the expectation that an electron-withdrawing $\mathrm{N}-\mathrm{Ar}$ group leads to increased $\Delta H$ / $\Delta S$ due to stronger metal-ligand $\pi$-bonding.

For compound 6, which has an additional $\mathrm{C}_{6} \mathrm{~F}_{5}$ substituent at the $\mathrm{C}-\mathrm{Ar}^{3}$ position, the solution characterization data are

Table 3. Thermodynamic Parameters for the Equilibrium between $S=0$ and $S=2$ Spin States in Toluene- $d_{8}$ Solution for Compounds 1-7

\begin{tabular}{|c|c|c|c|c|c|c|c|}
\hline & $1^{a}$ & $2^{b}$ & 3 & $4^{b}$ & 5 & 6 & $7^{b}$ \\
\hline$\Delta H\left(\mathrm{~kJ} \mathrm{~mol}^{-1}\right)$ & $22.2 \pm 0.3$ & $8.5 \pm 0.4$ & $26.3 \pm 0.1$ & $12.6 \pm 1.0$ & $19.0 \pm 0.4$ & - & $37.5 \pm 1.6$ \\
\hline$\Delta S\left(\mathrm{~J} \mathrm{~mol}^{-1} \mathrm{~K}^{-1}\right)$ & $64 \pm 1$ & $45 \pm 4$ & $78 \pm 1$ & $67 \pm 5$ & $70 \pm 1$ & - & $85 \pm 5$ \\
\hline$T_{1 / 2}^{c}(\mathrm{~K})$ & $345 \pm 7$ & $192 \pm 18$ & $340 \pm 2$ & $188 \pm 21$ & $271 \pm 8$ & - & $444 \pm 34$ \\
\hline
\end{tabular}

${ }^{a}$ Data reproduced from ref 14 a. ${ }^{b}$ Estimated from fitting a limited temperature range. ${ }^{c}$ The uncertainty in $T_{1 / 2}$ is obtained by using error propagation from $\Delta H$ and $\Delta S$. 
indicative of a high-spin ground state also at low temperature, as shown by a magnetic moment of $4.9-5.1 \mu_{\mathrm{B}}$ across the temperature range studied $(217-348 \mathrm{~K})$. The spectral changes in the VT ${ }^{1} \mathrm{H}$ NMR studies provide evidence for a spin equilibrium at the lowest temperatures (a departure from Curie behavior), which may indicate population of either the intermediate-spin $(S=1)$ state that is observed by crystallography or a low-spin $(S=0)$ complex similar to that present for the other compounds. However, the population of a different spin state is too small at these temperatures to allow an unambiguous interpretation of the changes that occur.

Finally, the spin-crossover properties of compound 7 were evaluated in solution. At room temperature, the ${ }^{1} \mathrm{H}$ NMR spectrum of 7 shows resonances in the diamagnetic range, and the number of signals is indicative of $C_{2 v}$ symmetry. While most peaks are sharp, those corresponding to the $o-\mathrm{CH}(\mathrm{N}-$ $\mathrm{Ph}$ ) and the OMe groups appear broadened, suggesting that also 7 may show a temperature-dependent equilibrium between a LS $(S=0)$ diamagnetic state and a HS $(S=2)$ paramagnetic state. Indeed, when the temperature was increased, the resonances of 7 broaden substantially and shift away from their diamagnetic values (Figure 9).

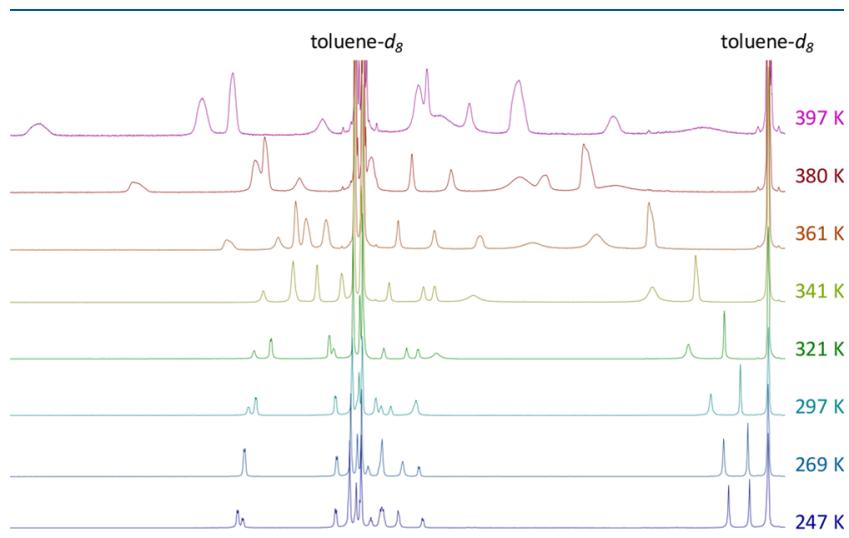

$\begin{array}{llllllllllllllllllllllll}11.0 & 10.5 & 10.0 & 9.5 & 9.0 & 8.5 & 8.0 & 7.5 & 7.0 & 6.5 & 6.0 & 5.5 & 5.0 & 4.5 & 4.0 & 3.5 & 3.0 & 2.5 & 2 . c\end{array}$

Figure 9. ${ }^{1} \mathrm{H}$ NMR spectra of 7 recorded between 247 and $397 \mathrm{~K}$ (toluene- $d_{8}, 500 \mathrm{MHz}$ ).

The variable-temperature NMR data can be modeled with the equilibrium parameters $\Delta H=37.5 \pm 1.6 \mathrm{~kJ} \mathrm{~mol}^{-1}$ and $\Delta S$ $=85 \pm 5 \mathrm{~J} \mathrm{~mol}^{-1} \mathrm{~K}^{-1}$. The increase in $\Delta H$ compared to the other compounds discussed above indicates that there is a substantial additional enthalpic penalty upon changing the spin state from singlet to quintet. A key question surrounding the spin-crossover in 7 is whether or not the $\mathrm{Fe} \cdots \mathrm{OMe}$ interaction is retained in solution; that is, does it involve a change in the coordination sphere around the Fe center, or does the ligand maintain the same coordination mode in both spin states? Several lines of experimental and computational evidence point toward retention of the tridentate NNO coordination mode of the ligand in both spin states, resulting in an octahedral geometry for 7 throughout. First, although 7 is predominantly low-spin at room temperature, its OMe resonance is somewhat broadened. This is likely because it is in close proximity to the paramagnetic center and is thus noticeably affected, also when the population of high-spin 7 is still very low. In addition, the spin-state equilibrium in 7 is characterized by a value of $\Delta S$ $\left(85 \pm 5 \mathrm{~J} \mathrm{~mol}^{-1} \mathrm{~K}^{-1}\right)$ that is only marginally larger than that of the others; loss of the Fe... OMe interaction in the high-spin state is expected to lead to a much larger entropy change. Finally, we performed density functional theory calculations on 7 in both spin states, with and without the $\mathrm{Fe} \cdots \mathrm{OMe}$ interaction ( $7_{\text {calc }}$ and $7^{\prime}$ calc, respectively; see the Supporting Information for details). The results of geometry optimizations with a def2-TZVP basis set ${ }^{20}$ using either pure $(\mathrm{BP} 86)^{21}$ or hybrid functionals (TPSSh, ${ }^{22} \mathrm{~B}^{2} \mathrm{LYP}^{23}$ ) all indicate that structures with the $\mathrm{Fe} \cdots \mathrm{OMe}$ interaction are favored over those in which the OMe group points away from the metal center. The optimized geometries for $7_{\text {calc }}$ in the low-spin state have short $\mathrm{Fe}-\mathrm{O}$ bonds of $2.14-2.21 \AA$, which are elongated to $2.43-2.51 \AA$ in the $S=2$ minima; the shortest bonds are found for the TPSSh geometries and the longest for BP86. Although, as expected, there are large differences between these functionals for the computed energy differences between the different spin states, ${ }^{24}$ it is important to note that the calculations indicate that coordination of the OMe groups is stabilizing in both spin states, regardless of the functional used $\left(\Delta G_{\text {calc }}>23.7 \mathrm{~kJ} \mathrm{~mol}^{-1}\right)$. Analysis of the frontier molecular orbitals of (low-spin) 7 calc shows that the additional interaction with the weak OMe donor groups does not lead to a substantial change in ligand-field strength in comparison to a structure in which the OMe groups are rotated away from the metal center ( $7^{\prime}$ calc; see Figures S54 and S55 for a comparison of the canonical DFT orbitals). In fact, the HOMO-LUMO energy gap at the BP86/def2-TZVP level is somewhat smaller in the structure with the Fe...OMe interaction (LS-7 $7_{\text {calc }}: 9227$ $\mathrm{cm}^{-1}$ ) compared to without (LS-7 $\left.{ }_{\text {calc }}^{\prime}: 10466 \mathrm{~cm}^{-1}\right){ }^{25}$ Analysis of the intrinsic bonding orbitals ${ }^{26}$ at the BP86/def2TZVP geometry shows that while the change from a four- to six-coordinate environment does result in somewhat different localized Fe orbitals, in both cases there clearly is a substantial degree of metal-ligand $\pi$-covalency (Figure 10). A similar analysis using the B3LYP and TPSSh functionals at the corresponding minima for $7_{\text {calc }}$ shows that the intrinsic bonding orbitals are qualitatively similar for TPSSh. On the other hand, the B3LYP results show less covalent $\mathrm{Fe}-\mathrm{N}$ bonds, which is reflected by a lower $\mathrm{N}$-contribution to the relevant

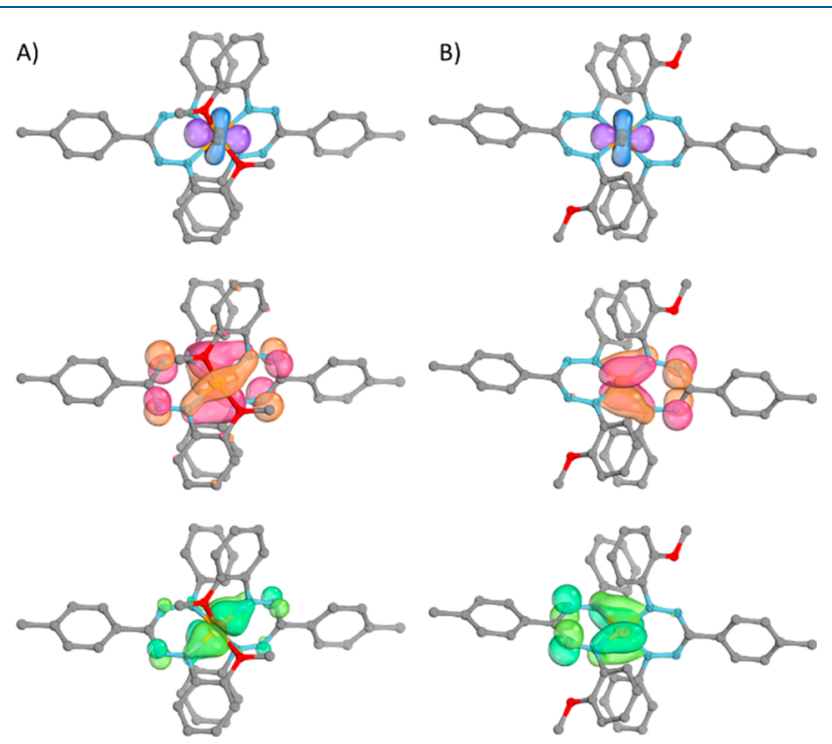

Figure 10. Representation of intrinsic bonding orbitals at the BP86/ def2-TZVP minima, both with $\left(7_{\text {calc }} ;(\mathrm{A})\right)$ and without $\mathrm{Fe}-\mathrm{O}$ interaction $\left(7^{\prime}{ }_{\text {calc }} ;(\mathrm{B})\right)$. 
IBOs and a smaller Wiberg bond index for the $\mathrm{Fe}-\mathrm{N}$ bonds (Table S6).

To corroborate the NMR data, we subsequently performed variable-temperature $\mathrm{UV}$-vis spectroscopic measurements on all compounds. Dilute solutions in toluene $\left(\mathrm{ca} .10^{-5} \mathrm{M}\right)$ were analyzed at temperatures down to $183 \mathrm{~K}$. The fact that we could access lower temperatures in the UV-vis spectrometer was particularly helpful in the analysis of compounds 2 and 4 , for which spin-crossover has a relatively low $T_{1 / 2}$. The thermodynamic parameters obtained from the fitting of the UV-vis data are congruent with those found from the NMR analysis (see Table S4).

Although the UV-vis spectra of the compounds in this series often are equilibrium mixtures that contain both spin states, the data at the extremes of the temperature range represent predominantly low- or high-spin (at low or high temperature, respectively), and these were taken to extract the absorption maxima of the other spin state by scaled subtraction (see the Supporting Information for details). The only exception is compound 6, the UV-vis spectrum of which does not change appreciably with temperature, and $\mathbf{6}$ is predominantly found in the high-spin state (Figure 11A). The
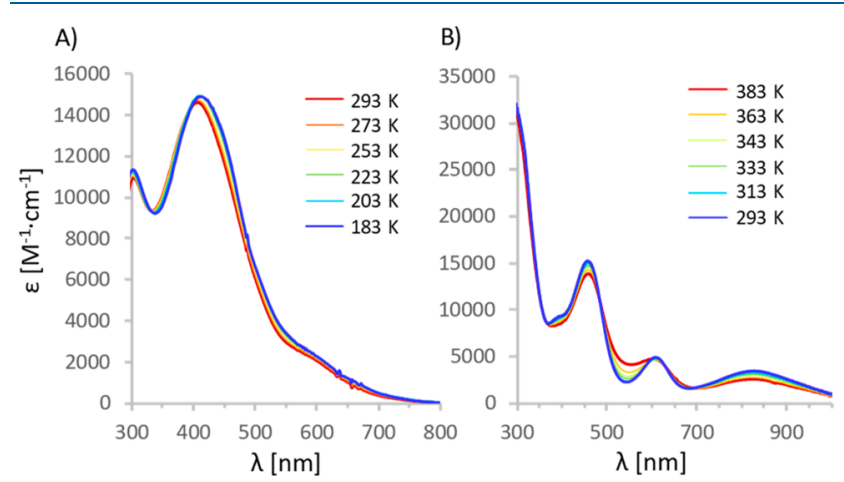

Figure 11. UV/vis spectra in toluene for (A) compound 6 recorded between 183 and $293 \mathrm{~K}$ and (B) compound 7 recorded between 293 and $383 \mathrm{~K}$.

LS spectra for 2-5 show two intense bands in the visible range with absorption maxima between $375-445$ and $515-575 \mathrm{~nm}$ which are assigned to ligand-based $\pi-\pi^{*}$ transitions. ${ }^{14}$ In the HS state, the two bands are bathochromically shifted (around 390-510 and 580-630 nm, respectively), and the lowest energy band shows a significantly lower intensity (Figure S24).

The UV-vis spectrum of compound 7 is distinct from the others as it shows three absorption maxima in the LS state $(\lambda=$ 459, 608, and $828 \mathrm{~nm}$; see Figure 11B). The lowest-energy transition in 7 is much broader and occurs at significantly lower energy than in the other compounds. Thus, the presence of the additional OMe donor groups in 7 results in an additional low-lying excited state that is a distinguishing feature of this compound.

\section{CONCLUSIONS}

In this work, we have extended the series of bis(formazanate)iron complexes to systems featuring nonsymmetric ligands with two different $\mathrm{N}-\mathrm{Ar}$ substituents. We have demonstrated that the spin-crossover behavior of this class of compounds may be modulated via modification of the ligand using different strategies: electronic effects, steric effects, $\pi$-stacking interactions, and ligand denticity. The formazanate ligands reported in this work allowed crystallographic characterization of structures with different coordination geometries and spin states: pseudo-tetrahedral low-spin (3), tetrahedral high-spin $(4,6 a)$, square-planar intermediate-spin $(6 \mathbf{b})$, and octahedral low-spin (7). Moreover, $\mathbf{6 b}$ is shown to thermally switch in the solid state to $\mathbf{6 a}$, undergoing an incomplete spin-changecoupled square-planar-tetrahedral isomerization, which is rare for iron(II) compounds. The combination of sterics, $\pi$-stacking interactions, and electronic effects provides a plethora of tools that can be used to substantially affect spin-crossover behavior in this class of compounds. Overall, we were able to tune the system to obtain solution spin-crossover properties that range from very low $T_{1 / 2}(\sim 190 \mathrm{~K}$ in 2 and 4$)$ to well above room temperature ( $444 \mathrm{~K}$ in 7 ). Computational data suggest that the spin-crossover in the six-coordinate bis(formazanate)iron(II) complex (7) is of similar nature to that previously described for the four-coordinate derivatives ${ }^{14}$ and originates from a large degree of covalency in the $\mathrm{Fe}-\mathrm{N}$ bonds due to metal $\rightarrow$ ligand $\pi$-back-donation. Given the relevance of understanding and tuning spin-state-dependent reactivity, we anticipate that this study provides useful insight into ways to fine-tune the spinstate energetics in $\mathrm{Fe}(\mathrm{II})$ complexes.

\section{EXPERIMENTAL SECTION}

General Considerations. All manipulations were performed under nitrogen or argon by using standard glovebox, Schlenk, and vacuum-line techniques. THF (Aldrich, anhydrous, 99.8\%) was dried by percolation over columns of $\mathrm{Al}_{2} \mathrm{O}_{3}$ (Fluka); toluene, hexane, and pentane (Aldrich, anhydrous, 99.8\%) were passed over columns of $\mathrm{Al}_{2} \mathrm{O}_{3}$ (Fluka), BASF R3-11-supported $\mathrm{Cu}$ oxygen scavenger, and molecular sieves (Aldrich, $4 \AA$ ). THF- $d_{8}$ (Euriso-top) and Tol- $d_{8}$ (Aldrich) were vacuum transferred from $\mathrm{Na} / \mathrm{K}$ alloy and stored under nitrogen.

The compounds $2 \mathbf{H}^{27} \mathbf{3} \mathbf{H}^{28} \mathbf{4} \mathbf{H},,^{29} \mathbf{5} \mathbf{H}^{28} \mathbf{6 H},{ }^{30}$ and $\mathrm{Fe}[\mathrm{N}$ $\left.\left(\mathrm{SiMe}_{3}\right)_{2}\right]_{2}{ }^{31}$ were synthesized according to the literature procedures. Ligand $7 \mathbf{H}$ was prepared according to a slightly adapted version of a literature method ${ }^{28,32}$ (see the Supporting Information for a detailed description). Sodium carbonate (Merck), tetrabutylammonium bromide (Sigma-Aldrich, 99\%), o-anisidine (Sigma-Aldrich, >99\%), hydrochloric acid (Boom B.V., 37-38\%), and sodium nitrite (Sigma-Aldrich, 99\%) were used as received.

NMR spectra were recorded on a Varian Mercury 400, Inova 500, or Bruker $600 \mathrm{MHz}$ spectrometer. The ${ }^{1} \mathrm{H}$ and ${ }^{13} \mathrm{C}$ NMR spectra were referenced internally by using the residual solvent resonances and reported in ppm relative to TMS (0 ppm). The assignments of NMR resonances were aided by COSY, HMQC, HSQC, and HMBC experiments using standard pulse sequences.

Elemental analyses were performed by the analytical laboratory of the Institute of Inorganic Chemistry at the University of Göttingen using an Elementar Vario EL III instrument.

Synthesis of $\mathrm{Fe}\left[\mathrm{PhNNC}\left(\mathrm{C}_{6} \mathrm{~F}_{5}\right) \mathrm{NNPh}\right]_{2}$ (2). A dark-orange solution of L2H $(516.5 \mathrm{mg}, 1.32 \mathrm{mmol})$ in THF $(20 \mathrm{~mL})$ was added to a green solution of $\mathrm{Fe}\left[\mathrm{N}\left(\mathrm{SiMe}_{3}\right)_{2}\right]_{2}(247.9 \mathrm{mg}, 0.66 \mathrm{mmol})$ in THF $(10 \mathrm{~mL})$. The reaction mixture was stirred overnight at room temperature, leading to a red-brick-colored solution. The volatiles were removed under a vacuum, and the product was extracted in THF. Slow diffusion of hexane into the THF solution at $-30{ }^{\circ} \mathrm{C}$ resulted in $303.8 \mathrm{mg}$ of dark-brown powder $(0.36 \mathrm{mmol}, 55 \%) .{ }^{1} \mathrm{H}$ NMR $\left(500 \mathrm{MHz}, \mathrm{THF}-d_{8}, 25{ }^{\circ} \mathrm{C}\right): \delta 24.61(4 \mathrm{H}, \mathrm{Ph} m-\mathrm{CH}),-9.31$ $(2 \mathrm{H}, \mathrm{Ph} p-\mathrm{CH}),-13.40$ (br, $4 \mathrm{H}, \mathrm{Ph} o-\mathrm{CH}) \mathrm{ppm} .{ }^{19} \mathrm{~F}$ NMR $(470$ MHz, THF- $\left.d_{8},-65{ }^{\circ} \mathrm{C}\right): \delta-111.79\left(2 \mathrm{~F}, \mathrm{C}_{6} \mathrm{~F}_{5}, o-\mathrm{CF}\right),-130.81(1 \mathrm{~F}$, $\mathrm{C}_{6} \mathrm{~F}_{5}, p$-CF), $-157.34 \mathrm{ppm}\left(2 \mathrm{~F}, \mathrm{C}_{6} \mathrm{~F}_{5}, m-\mathrm{CF}\right)$. HMQC-NMR (125 MHz, THF- $\left.d_{8},+25{ }^{\circ} \mathrm{C}\right): \delta 107.2(\mathrm{Ph} m-\mathrm{CH}), 3.98 \mathrm{ppm}(\mathrm{Ph} p-\mathrm{CH})$. The signal of $\mathrm{Ph} o-\mathrm{CH}$ in the HMQC spectrum was not visible due to line broadening.

Synthesis of Fe[PhNNC(p-Tol)NNMes $]_{2}$ (3). $\mathrm{Fe}\left[\mathrm{N}\left(\mathrm{SiMe}_{3}\right)_{2}\right]_{2}$ $(0.71 \mathrm{~g} 1.88 \mathrm{mmol})$ was dissolved in THF $(15 \mathrm{~mL})$, and a solution of 
Table 4. Crystallographic Data for Compounds 3, 4, 6a, 6b, and 7

\begin{tabular}{|c|c|c|c|c|c|}
\hline & 3 & 4 & $6 a$ & $6 b$ & 7 \\
\hline chem formula & $\mathrm{C}_{46} \mathrm{H}_{46} \mathrm{~N}_{8} \mathrm{Fe}$ & $\mathrm{C}_{50} \mathrm{H}_{46} \mathrm{~F}_{10} \mathrm{FeN}_{8}$ & $\mathrm{C}_{44} \mathrm{H}_{22} \mathrm{~F}_{20} \mathrm{FeN}_{8}$ & $\mathrm{C}_{44} \mathrm{H}_{22} \mathrm{~F}_{20} \mathrm{FeN}_{8}$ & $\mathrm{C}_{46} \mathrm{H}_{46} \mathrm{FeN}_{8} \mathrm{O}_{3}$ \\
\hline$M_{\mathrm{r}}$ & 766.76 & 1004.80 & 1098.54 & 1098.54 & 814.76 \\
\hline cryst syst & triclinic & triclinic & monoclinic & triclinic & monoclinic \\
\hline color, habit & red, block & red, block & brown, block & red, block & green, needle \\
\hline size $(\mathrm{mm})$ & $0.23 \times 0.18 \times 0.11$ & $0.42 \times 0.26 \times 0.09$ & $0.30 \times 0.17 \times 0.15$ & $0.34 \times 0.20 \times 0.09$ & $0.49 \times 0.06 \times 0.02$ \\
\hline space group & $P-1$ & $P-1$ & $P 21 / c$ & $P-1$ & $P 21 / c$ \\
\hline$a(\AA)$ & $8.5063(5)$ & $12.3467(8)$ & $12.7118(6)$ & $7.2786(6)$ & $12.0477(5)$ \\
\hline$b(\AA)$ & $11.3217(7)$ & $12.4167(8)$ & $20.5795(10)$ & $12.5743(10)$ & $24.0684(9)$ \\
\hline$c(\AA)$ & $21.5733(13)$ & $15.4105(10)$ & $17.4336(7)$ & $12.6798(9)$ & $14.6588(5)$ \\
\hline$\alpha(\mathrm{deg})$ & $93.547(2)$ & $86.354(2)$ & 90 & $118.595(2)$ & 90 \\
\hline$\beta(\operatorname{deg})$ & $94.372(2)$ & $88.205(2)$ & $95.991(2)$ & $99.168(3)$ & $109.140(2)$ \\
\hline$\gamma(\operatorname{deg})$ & $109.254(2)$ & $83.349(2)$ & 90 & $94.529(3)$ & 90 \\
\hline$V\left(\AA^{3}\right)$ & $1947.3(2)$ & $2341.2(3)$ & $4535.8(4)$ & $989.67(13)$ & $4015.6(3)$ \\
\hline$Z$ & 2 & 2 & 4 & 1 & 4 \\
\hline$\rho_{\text {calc }} \mathrm{g} \mathrm{cm}^{-3}$ & 1.308 & 1.425 & 1.609 & 1.843 & 1.348 \\
\hline radiation $[\AA]$ & Mo $\mathrm{K} \alpha 0.71073$ & Mo $\mathrm{K} \alpha 0.71073$ & Mo $\mathrm{K} \alpha 0.71073$ & Mo $\mathrm{K} \alpha 0.71073$ & $\mathrm{Cu} \mathrm{K} \alpha 1.54178$ \\
\hline$\mu(\operatorname{Mo~K} \alpha), \mathrm{mm}^{-1}$ & 0.432 & 0.407 & 0.458 & 0.525 & \\
\hline$\mu(\mathrm{Cu} \mathrm{K} \alpha), \mathrm{mm}^{-1}$ & & & & & 3.433 \\
\hline$F(000)$ & 808 & 1036 & 2192 & 548 & 1712 \\
\hline temp $(\mathrm{K})$ & $100(2)$ & $100(2)$ & $200(2)$ & $100(2)$ & $100(2)$ \\
\hline$\theta$ range $(\mathrm{deg})$ & $2.76-27.16$ & $3.04-27.92$ & $2.88-26.38$ & $2.88-27.94$ & $3.68-65.14$ \\
\hline data collected $(h, k, l)$ & $\begin{array}{l}-10: 10 ;-13: 14 ; \\
-27: 27\end{array}$ & $\begin{array}{l}-16: 16 ;-16: 16 ; \\
\quad-20: 20\end{array}$ & $\begin{array}{l}-15: 15 ;-25: 25 ; \\
\quad-21: 21\end{array}$ & $-9: 9 ;-16: 16 ;-16: 16$ & $\begin{array}{l}-14: 14 ;-28: 28 \\
\quad-17: 16\end{array}$ \\
\hline no. of rflns collected & 60240 & 70899 & 54918 & 47685 & 32490 \\
\hline no. of indpndt collected & 8538 & 11211 & 9089 & 4755 & 6743 \\
\hline $\begin{array}{l}\text { observed reflns } F_{\mathrm{o}} \geq \\
2.0 \sigma\left(F_{\mathrm{o}}\right)\end{array}$ & 7238 & 9251 & 6346 & 4557 & 5373 \\
\hline$R(F)(\%)$ & 3.46 & 3.36 & 4.32 & 2.55 & 4.61 \\
\hline$w R(F 2)(\%)$ & 8.03 & 8.05 & 9.93 & 2.55 & 12.01 \\
\hline GooF & 1.045 & 1.040 & 1.030 & 7.07 & 1.037 \\
\hline weighting $a, b$ & $0.0267,1.5260$ & $0.0311,1.2677$ & $0.0324,3.4691$ & $0.0372,0.6125$ & $0.0552,2.9707$ \\
\hline params refined & 504 & 687 & 664 & 334 & 527 \\
\hline $\min , \max$ resid dens & $-0.427,0.295$ & $-0.280,0.375$ & $-0.260,0.264$ & $-0.451,0.379$ & $-0.346,0.689$ \\
\hline
\end{tabular}

L3H (1.31 g, $3.66 \mathrm{mmol})$ in THF $(15 \mathrm{~mL})$ was added. The reaction mixture was stirred for 2 days at room temperature, leading to a darkred solution. The solution was filtered, and the volatiles were removed under a vacuum. Recrystallization by slow diffusion of hexane into a THF solution gave $0.62 \mathrm{~g}$ of brown powder $(0.83 \mathrm{mmol}, 44 \%$ yield $)$. ${ }^{1} \mathrm{H}$ NMR $\left(600 \mathrm{MHz}, \mathrm{THF}-d_{8}, 25^{\circ} \mathrm{C}\right): \delta 12.48(2 \mathrm{H}, \mathrm{Ph} m-\mathrm{CH}), 10.94$ $(2 \mathrm{H}, p$-Tol $m-\mathrm{CH}), 10.56\left(1 \mathrm{H}, \mathrm{Mes} m-\mathrm{CH}^{\mathrm{A}}\right), 9.76(3 \mathrm{H}, p$-Tol $p$ $\left.\mathrm{CH}_{3}\right), 8.66\left(6 \mathrm{H}, \mathrm{Mes} o-\mathrm{CH}_{3}\right), 8.45\left(1 \mathrm{H}, \mathrm{Mes} m-\mathrm{CH}^{\mathrm{B}}\right), 3.96(2 \mathrm{H}, p-$ Tol $o-\mathrm{CH}), 0.42(1 \mathrm{H}, \mathrm{Ph} p-\mathrm{CH}),-0.70\left(3 \mathrm{H}, \mathrm{Mes} p-\mathrm{CH}_{3}\right),-1.44$ ppm $(2 \mathrm{H}, \mathrm{Ph} o-\mathrm{CH}) .{ }^{1} \mathrm{H}$ NMR $\left(500 \mathrm{MHz}\right.$, THF- $\left.d_{8},-55^{\circ} \mathrm{C}\right): \delta 8.06$ $(2 \mathrm{H}, p$-Tol $o-\mathrm{CH}), 7.37(2 \mathrm{H}, p-\mathrm{Tol} m-\mathrm{CH}), 7.25(2 \mathrm{H}, \mathrm{Ph} m-\mathrm{CH})$, $7.11\left(1 \mathrm{H}\right.$, Mes $\left.m-\mathrm{CH}^{\mathrm{A}}\right), 7.05(1 \mathrm{H}, \mathrm{Ph} p-\mathrm{CH}), 6.65(1 \mathrm{H}$, Mes $m$ $\left.\mathrm{CH}^{\mathrm{B}}\right), 6.47(2 \mathrm{H}, \mathrm{Ph} o-\mathrm{CH}), 2.58\left(6 \mathrm{H}, p-\mathrm{Tol} p-\mathrm{CH}_{3}\right.$ and Mes $o$ $\left.\mathrm{CH}_{3}{ }^{\mathrm{A}}\right), 1.69\left(3 \mathrm{H}\right.$, Mes $\left.o-\mathrm{CH}_{3}{ }^{\mathrm{B}}\right), 0.41 \mathrm{ppm}\left(3 \mathrm{H}\right.$, Mes $\left.p-\mathrm{CH}_{3}\right) \cdot{ }^{13} \mathrm{C}$ NMR (125 MHz, THF- $d_{8},-55^{\circ} \mathrm{C}$ ): $\delta 144.5$ (Ph ipso-C), 142.3 (Mes ipso-C), 141.4 (NCN), 137.8 (ipso-C), 135.6 (ipso-C), 134.2 (ipso-C), 133.9 (Mes $m$-C), 133.7 (Ph p-C), 133.3 (p-tol o-C), 133.2 (Ph $o$-C), 132.9 ( $p$-tol $m$-C), 131.9 ( $\mathrm{Ph} m$-C), $24.7\left(\mathrm{Mes} o-\mathrm{CH}_{3}\right), 24.2$ ( $p$-tol $p$ $\left.\mathrm{CH}_{3}\right), 22.8\left(\mathrm{Mes} p-\mathrm{CH}_{3}\right), 22.0 \mathrm{ppm}\left(\mathrm{Mes} o-\mathrm{CH}_{3}\right)$. Anal. Calcd for $\mathrm{C}_{46} \mathrm{H}_{46} \mathrm{~N}_{8} \mathrm{Fe}: \mathrm{C}, 72.06$; H, 6.05; N, 14,61. Found: C, 72.54; H 5.82; $\mathrm{N}, 14.12$.

Synthesis of $\mathrm{Fe}\left[\mathrm{PhNNC}\left(\mathrm{C}_{6} \mathrm{~F}_{5}\right) \mathrm{NNMes}_{2}\right.$ (4). A dark-orange solution of $\mathbf{L} 4 \mathrm{H}(478.3 \mathrm{mg}, 1.11 \mathrm{mmol})$ in toluene $(40 \mathrm{~mL})$ was added to a green solution of $\mathrm{Fe}\left[\mathrm{N}\left(\mathrm{SiMe}_{3}\right)_{2}\right]_{2}(190.5 \mathrm{mg}, 0.506 \mathrm{mmol})$ in toluene $(10 \mathrm{~mL})$. The reaction mixture was stirred for 2 days at room temperature, leading to a brown solution. The volatiles were removed under a vacuum, and the product was extracted into toluene. Slow diffusion of hexane into the toluene solution resulted in 189.6 $\mathrm{mg}$ of dark-brown crystals $(0.206 \mathrm{mmol}, 41 \%) .{ }^{1} \mathrm{H}$ NMR $(500 \mathrm{MHz}$, toluene- $\left.d_{8}, 25^{\circ} \mathrm{C}\right): \delta 35.51(3 \mathrm{H}), 30.98(3 \mathrm{H}), 28.44(2 \mathrm{H} \mathrm{Ph} m-\mathrm{CH})$,
$21.38(1 \mathrm{H}), 12.61(1 \mathrm{H}),-8.71(3 \mathrm{H}),-19.26(1 \mathrm{H}, \mathrm{Ph} p-\mathrm{CH})$, $-23.52(2 \mathrm{H} \mathrm{Ph} o-\mathrm{CH})$ ppm. ${ }^{19} \mathrm{~F}$ NMR $\left(470 \mathrm{MHz}\right.$, toluene- $d_{8}, 25$ $\left.{ }^{\circ} \mathrm{C}\right): \delta-103.93\left(2 \mathrm{~F}, \mathrm{C}_{6} \mathrm{~F}_{5}, o-\mathrm{CF}\right),-125.22\left(1 \mathrm{~F}, \mathrm{C}_{6} \mathrm{~F}_{5}, p-\mathrm{CF}\right)$, $-147.38 \mathrm{ppm}\left(2 \mathrm{~F}, \mathrm{C}_{6} \mathrm{~F}_{5}, m-\mathrm{CF}\right)$.

Synthesis of $\mathrm{Fe}\left[\mathrm{C}_{6} \mathrm{~F}_{5} \mathrm{NNC}(p \text {-Tol)NNMes }]_{2}\right.$ (5). A red-brickcolored solution of $\mathbf{L S H}(1.41 \mathrm{~g}, 3.16 \mathrm{mmol})$ in toluene $(40 \mathrm{~mL})$ was added to a green solution of $\mathrm{Fe}\left[\mathrm{N}\left(\mathrm{SiMe}_{3}\right)_{2}\right]_{2}(0.60 \mathrm{~g}, 1.58 \mathrm{mmol})$ in toluene $(10 \mathrm{~mL})$. The reaction mixture was stirred overnight at room temperature, leading to a brown solution. The solution was filtered, and the volatiles were removed under a vacuum; the obtained dark solid was quickly washed with cold hexane, giving $1.28 \mathrm{~g}(1.35 \mathrm{mmol}$, $85 \%$ ) of crude product. Any attempt to recrystallize the product was unsuccessful. ${ }^{1} \mathrm{H}$ NMR $\left(400 \mathrm{MHz}, \mathrm{C}_{6} \mathrm{D}_{6}, 25^{\circ} \mathrm{C}\right): \delta 24.23(3 \mathrm{H}), 17.22$ $(2 \mathrm{H}), 15.52(3 \mathrm{H}), 14.15(2 \mathrm{H}), 12.84\left(6 \mathrm{H}, \mathrm{Mes} o-\mathrm{CH}_{3}\right),-6.20 \mathrm{ppm}$ $(2 \mathrm{H}) .{ }^{19} \mathrm{~F}$ NMR (375 MHz, $\left.\mathrm{C}_{6} \mathrm{D}_{6}, 25{ }^{\circ} \mathrm{C}\right): \delta-91.63(1 \mathrm{~F}, p-\mathrm{CF})$, $-163.25 \mathrm{ppm}(2 \mathrm{~F}, m-\mathrm{CF})$. The signal of $\mathrm{C}_{6} \mathrm{~F}_{5} o$-CF was not visible due to line broadening.

Synthesis of $\mathrm{Fe}\left[\mathrm{C}_{6} \mathrm{~F}_{5} \mathrm{NNC}\left(\mathrm{C}_{6} \mathrm{~F}_{5}\right) \mathrm{NNMes}_{2}\right.$ (6). A dark-orange solution of $6 \mathrm{H}(1.352 \mathrm{~g}, 2.587 \mathrm{mmol})$ in THF $(40 \mathrm{~mL})$ was added to a green solution of $\mathrm{Fe}\left[\mathrm{N}\left(\mathrm{SiMe}_{3}\right)_{2}\right]_{2}(0.489 \mathrm{~g} 1.299 \mathrm{mmol})$ in THF $(20 \mathrm{~mL})$. The reaction mixture was stirred for $5 \mathrm{~h}$, leading to a brown solution. The volatiles were removed under a vacuum, and a brown solid was collected in $70 \%$ yield $(1.009 \mathrm{~g}, 0.919 \mathrm{mmol})$. The solid was recrystallized from refluxing hexane which afforded crystals of $\mathbf{6 a}$ suitable for X-ray diffraction. Alternatively, diffusion of hexane into a THF solution afforded single crystals of $6 \mathbf{b}$. ${ }^{1} \mathrm{H}$ NMR $(500 \mathrm{MHz}$, toluene- $\left.d_{8}, 25{ }^{\circ} \mathrm{C}\right): \delta 20.94\left(3 \mathrm{H}\right.$, Mes $\left.p-\mathrm{CH}_{3}\right), 14.77(2 \mathrm{H}$, Mes $m$ $\mathrm{CH}), 11.22 \mathrm{ppm}\left(6 \mathrm{H}\right.$, Mes $\left.o-\mathrm{CH}_{3}\right) .{ }^{19} \mathrm{~F}$ NMR $\left(375 \mathrm{MHz}\right.$, toluene- $d_{8}$, $\left.25{ }^{\circ} \mathrm{C}\right): \delta-93.78(1 \mathrm{~F}, p$-CF) $,-106.37(2 \mathrm{~F}, o-\mathrm{CF}),-130.67(1 \mathrm{~F}, p-$ $\mathrm{CF}),-154.58(2 \mathrm{~F}, m-\mathrm{CF}),-160.23 \mathrm{ppm}(2 \mathrm{~F}, m-\mathrm{CF})$. The signal of $o-$ 
$\mathrm{CF}$ of $\mathrm{N}-\mathrm{C}_{6} \mathrm{~F}_{5}$ was not visible due to line broadening. Note: NMR spectra are identical for $\mathbf{6 a}$ and $\mathbf{6 b}$. Anal. Calcd for $\mathrm{C}_{44} \mathrm{H}_{22} \mathrm{~N}_{8} \mathrm{~F}_{20} \mathrm{Fe}$ : C, 48.11; H, 2.02; N, 10,20. Found: C, 48.25; H 1.85; N, 10.04 .

Synthesis of $\mathrm{Fe}[\mathrm{PhNNC}(p-\mathrm{Tol}) \mathrm{NN}(\mathrm{o}-\mathrm{An})]_{2} \cdot 0.5$ (THF) (7). A fuchsia THF $(10 \mathrm{~mL})$ solution of $\mathbf{L} 7 \mathrm{H}(96.4 \mathrm{mg}, 0.28 \mathrm{mmol})$ was added to a green solution of $\mathrm{Fe}\left[\mathrm{N}\left(\mathrm{SiMe}_{3}\right)_{2}\right]_{2}(52.7 \mathrm{mg}, 0.14 \mathrm{mmol})$ in $5 \mathrm{~mL}$ of THF. The reaction mixture was stirred for 3 days at room temperature, leading to a brown solution that was filtered through a $0.2 \mu \mathrm{m}$ syringe filter, and slow diffusion of hexane into the THF solution afforded 7 as dark needles in $70 \%$ yield $(76.6 \mathrm{mg}, 0.098$ mmol). ${ }^{1} \mathrm{H}$ NMR $\left(400 \mathrm{MHz}, \mathrm{C}_{6} \mathrm{D}_{6}, 25{ }^{\circ} \mathrm{C}\right): \delta=8.43(\mathrm{~d}, J=7.6 \mathrm{~Hz}$, $1 \mathrm{H}, o$-An $\left.{ }^{\delta} \mathrm{CH}\right), 8.36(\mathrm{~d}, J=7.9 \mathrm{~Hz}, 2 \mathrm{H}, p$-tolyl $o-\mathrm{CH}), 7.37(\mathrm{~d}, J=$ $7.7 \mathrm{~Hz}, 2 \mathrm{H}, p$-tolyl $m$-CH), $7.08\left(\mathrm{t}, J=7.2 \mathrm{~Hz}, 1 \mathrm{H}, o-\mathrm{An}{ }^{\gamma} \mathrm{CH}\right), 6.84$ $(\mathrm{d}, J=6.7 \mathrm{~Hz}, 2 \mathrm{H}, \mathrm{Ph} m-\mathrm{CH}), 6.75\left(\mathrm{t}, J=7.5 \mathrm{~Hz}, 1 \mathrm{H}, o-\mathrm{An}{ }^{\beta} \mathrm{CH}\right)$ $6.64(\mathrm{t}, J=7.3 \mathrm{~Hz}, 1 \mathrm{H}, \mathrm{Ph} p-\mathrm{CH}), 6.41(\mathrm{~m}, 1 \mathrm{H}, \mathrm{Ph} o-\mathrm{CH}), 6.30(\mathrm{~d}, J$ $\left.=7.9 \mathrm{~Hz}, 1 \mathrm{H}, o-\mathrm{An}{ }^{\alpha} \mathrm{CH}\right), 3.58(\mathrm{~m}, 1 \mathrm{H}, \mathrm{THF}),{ }^{a} 2.78(\mathrm{~s}, 3 \mathrm{H}, o-\mathrm{An}$ $\left.\mathrm{OCH}_{3}\right), 2.41\left(\mathrm{~s}, 3 \mathrm{H}, p\right.$-tolyl $\left.\mathrm{CH}_{3}\right), 1.42 \mathrm{ppm}(\mathrm{m}, 1 \mathrm{H}, \mathrm{THF}) .{ }^{a}{ }^{13} \mathrm{C}$ NMR (151 MHz, $\left.\mathrm{C}_{6} \mathrm{D}_{6}, 25{ }^{\circ} \mathrm{C}\right): \delta=169.7$ (Ph ipso-C), 152.8 (NCN), 151.6 (o-An ipso-COCH $\left.{ }_{3}\right), 150.4$ (o-An ipso-C), 137.0 (ptolyl ipso- $\mathrm{CCH}_{3}$ ), 136.4 (p-tolyl ipso-C), 128.8 ( $p$-tolyl $m$-CH), 127.4 ( $p$-tolyl o-CH), $127.3(\mathrm{Ph} m-\mathrm{CH}), 126.6(\mathrm{Ph} p-\mathrm{CH}) 124.6(\mathrm{Ph} o-$ $\mathrm{CH}), 124.4\left(\right.$ o-An $\left.{ }^{\beta} \mathrm{CH}\right), 123.2\left(\right.$ o-An $\left.{ }^{\gamma} \mathrm{CH}\right), 118.6\left(o-A n{ }^{\delta} \mathrm{CH}\right), 112.0$ $\left(o-\mathrm{An}{ }^{\alpha} \mathrm{CH}\right), 67.8$ (THF), ${ }^{a} 56.5$ (o-An $\left.\mathrm{OCH}_{3}\right), 25.8$ (THF), ${ }^{a} 21.0$ ppm ( $p$-tolyl $\mathrm{CH}_{3}$ ). Anal. Calcd for $\mathrm{C}_{44} \mathrm{H}_{42} \mathrm{~N}_{8} \mathrm{O}_{2.5} \mathrm{Fe}$ : C 67.87, $\mathrm{H}$ 5.44, $\mathrm{N}$ 14.39. Found: C 68.02, H 5.43, N 14.02.

X-ray Crystallography. Single crystals of compounds 3, 4, 6a, 6b, and 7 (directly obtained from the mother liquor) were mounted on top of a cryoloop and transferred into the cold nitrogen stream (100 K; $200 \mathrm{~K}$ for 6a) of a Bruker-AXS D8 Venture diffractometer. Data collection and reduction was done by using the Bruker software suite APEX $3{ }^{33}$ The final unit cell was obtained from the $x y z$ centroids of 9772 (3), 9845 (4), 9892 (6a), 9813 (6b), and 9876 (7) reflections after integration. A multiscan absorption correction was applied for compounds $3,4,6 \mathrm{a}$, and $\mathbf{6 b}$ based on the intensities of symmetryrelated reflections measured at different angular settings (SADABS). For compound 7, a numerical absorption correction was applied after indexing of the crystal faces in APEX3. The structures were solved by direct methods using SHELXS, ${ }^{34}$ and refinement of the structure was performed by using SHLELXL. ${ }^{35}$ From the refinement of $\mathbf{4}$ it was clear that the hexane solvent molecule was disordered. A two-site disorder model was used to describe this. The site-occupancy factor for the major disorder component refined to 0.72. Several of the atoms in the disordered solvent molecule gave nonpositive definite displacement parameters when refined freely, and ultimately DFIX and ISOR instructions were applied. The structure of 6 a was measured at $200 \mathrm{~K}$ because the data at $100 \mathrm{~K}$ indicated an (incomplete) phase transition (not further investigated). For all structures, the hydrogen atoms were generated by geometrical considerations, constrained to idealized geometries and allowed to ride on their carrier atoms with an isotropic displacement parameter related to the equivalent displacement parameter of their carrier atoms. Crystal data and details on data collection and refinement are presented in Table 4.

\section{ASSOCIATED CONTENT}

\section{(s) Supporting Information}

The Supporting Information is available free of charge at https://pubs.acs.org/doi/10.1021/acs.inorgchem.0c03593.

Full experimental and characterization data, computational details (PDF)

\section{Accession Codes}

CCDC 2036148-2036152 contain the supplementary crystallographic data for this paper. These data can be obtained free of charge via www.ccdc.cam.ac.uk/data_request/cif, or by emailingdata_request@ccdc.cam.ac.uk, or by contacting The Cambridge Crystallographic Data Centre, 12 Union Road, Cambridge CB2 1EZ, UK; fax: +44 1223336033.
AUTHOR INFORMATION

\section{Corresponding Author}

Edwin Otten - Stratingh Institute for Chemistry, University of Groningen, 9747, AG, Groningen, The Netherlands; ๑ orcid.org/0000-0002-5905-5108; Email: edwin.otten@ rug.nl

\section{Authors}

Francesca Milocco - Stratingh Institute for Chemistry, University of Groningen, 9747, AG, Groningen, The Netherlands

Folkert de Vries - Stratingh Institute for Chemistry, University of Groningen, 9747, AG, Groningen, The Netherlands

Harmke S. Siebe - Stratingh Institute for Chemistry, University of Groningen, 9747, AG, Groningen, The Netherlands

Silène Engbers - Stratingh Institute for Chemistry, University of Groningen, 9747, AG, Groningen, The Netherlands

Serhiy Demeshko - Institut für Anorganische Chemie, Universität Göttingen, 37077 Göttingen, Germany

Franc Meyer - Institut für Anorganische Chemie, Universität Göttingen, 37077 Göttingen, Germany; ๑ orcid.org/00000002-8613-7862

Complete contact information is available at:

https://pubs.acs.org/10.1021/acs.inorgchem.0c03593

\section{Notes}

The authors declare no competing financial interest.

\section{ACKNOWLEDGMENTS}

Financial support from The Netherlands Organization for Scientific Research (NWO) is gratefully acknowledged (VIDI grant to E.O.). We thank the Center for Information Technology of the University of Groningen for their support and for providing access to the Peregrine high performance computing cluster as well as Prof. Wesley Browne and Dr. Johannes Klein (University of Groningen) for access to VTUV/vis spectroscopy. S.D. and F.M. acknowledge support from the Universität Göttingen.

\section{ADDITIONAL NOTE}

${ }^{a}$ Crystals of 7 contain one THF per iron complex, but drying results in loss of part of the THF solvate molecules.

\section{REFERENCES}

(1) (a) Poli, R. Open-Shell Organometallics as a Bridge between Werner-Type and Low-Valent Organometallic Complexes. The Effect of the Spin State on the Stability, Reactivity, and Structure. Chem. Rev. 1996, 96, 2135-2204. (b) Hawrelak, E. J.; Bernskoetter, W. H.; Lobkovsky, E.; Yee, G. T.; Bill, E.; Chirik, P. J. Square planar vs tetrahedral geometry in four coordinate iron(II) complexes. Inorg. Chem. 2005, 44, 3103-3111.

(2) Hartwig, J. F. Organotransition Metal Chemistry: From Bonding to Catalysis; University Science Books: Sausalito, CA, 2010.

(3) Cirera, J.; Ruiz, E.; Alvarez, S. Stereochemistry and spin state in four-coordinate transition metal compounds. Inorg. Chem. 2008, 47, 2871-2889.

(4) (a) Collman, J. P.; Hoard, J. L.; Kim, N.; Lang, G.; Reed, C. A. Synthesis, stereochemistry, and structure-related properties of alpha, beta, gamma, delta-tetraphenylporphinatoiron(II). J. Am. Chem. Soc. 1975, 97, 2676-2681. (b) Kirner, J. F.; Dow, W.; Scheidt, W. R. Molecular stereochemistry of two intermediate-spin complexes. Iron(II) phthalocyanine and manganese(II) phthalocyanine. Inorg. 
Chem. 1976, 15, 1685-1690. (c) Strauss, S. H.; Silver, M. E.; Ibers, J. A. Iron(II) octaethylchlorine: structure and ligand affinity comparison with its porphyrin and isobacteriochlorin homologs. J. Am. Chem. Soc. 1983, 105, 4108-4109.

(5) Chatt, J.; Shaw, B. L. Alkyls and aryls of transition metals. Part IV. Cobalt(II) and iron(II) derivatives. J. Chem. Soc. 1961, 285.

(6) (a) Nijhuis, C. A.; Jellema, E.; Sciarone, T. J. J.; Meetsma, A.; Budzelaar, P. H. M.; Hessen, B. First-Row Transition Metal Bis(amidinate) Complexes; Planar Four-Coordination of $\mathrm{Fe}^{\mathrm{II}}$ Enforced by Sterically Demanding Aryl Substituents Eur. Eur. J. Inorg. Chem. 2005, 2005, 2089-2099. (b) Wurzenberger, X.; Piotrowski, H.; Klufers, P. A stable molecular entity derived from rare iron(II) minerals: the square-planar high-spin $\mathrm{d}^{6} \mathrm{Fe}(\mathrm{II}) \mathrm{O}_{4}$ chromophore Angew. Angew. Chem., Int. Ed. 2011, 50, 4974-4978. (c) Cantalupo, S. A.; Fiedler, S. R.; Shores, M. P.; Rheingold, A. L.; Doerrer, L. H. High-spin square-planar $\mathrm{Co}(\mathrm{II})$ and $\mathrm{Fe}(\mathrm{II})$ complexes and reasons for their electronic structure. Angew. Chem., Int. Ed. 2012 51, 1000-1005. (d) Pinkert, D.; Demeshko, S.; Schax, F.; Braun, B.; Meyer, F.; Limberg, C. A Dinuclear Molecular Iron(II) Silicate with Two High-Spin Square-Planar $\mathrm{FeO}_{4}$ Units. Angew. Chem., Int. Ed. 2013, 52, 5155-5158. (e) Liu, Y.; Luo, L.; Xiao, J.; Wang, L.; Song, Y.; Qu, J.; Luo, Y.; Deng, L. Four-Coordinate Iron(II) Diaryl Compounds with Monodentate N-Heterocyclic Carbene Ligation: Synthesis, Characterization, and Their Tetrahedral-Square Planar Isomerization in Solution. Inorg. Chem. 2015, 54, 4752-4760.

(7) (a) Holm, R. H.; Chakravorty, A.; Theriot, L. J. The Synthesis, Structures, and Solution Equilibria of Bis(pyrrole-2-aldimino)metal(II) Complexes. Inorg. Chem. 1966, 5, 625-635. (b) Wolny, J. A.; Rudolf, M. F.; Ciunik, Z.; Gatner, K.; Wołowiec, S. Cobalt(II) triazene 1-oxide bis(chelates). A case of planar (low spin)-tetrahedral (high spin) isomerism. J. Chem. Soc., Dalton Trans. 1993, 1611-1622. (c) Ingleson, M. J.; Pink, M.; Fan, H.; Caulton, K. G. Exploring the reactivity of four-coordinate $\mathrm{PNPCoX}$ with access to three-coordinate spin triplet PNPCo. Inorg. Chem. 2007, 46, 10321-10334.

(8) Gaazo, J. Plasticity of the coordination sphere of copper(II) complexes, its manifestation and causes. Coord. Chem. Rev. 1976, 19, 253-297.

(9) (a) Cambi, L.; Szegö, L. Über die magnetische Susceptibilität der komplexen Verbindungen. Ber. Dtsch. Chem. Ges. B 1931, 64, 25912598. (b) Kahn, O.; Martinez, C. J. Spin-Transition Polymers: From Molecular Materials Toward Memory Devices. Science 1998, 279, 4448. (c) Gütlich, P.; Garcia, Y.; Goodwin, H. A. Spin crossover phenomena in Fe(ii) complexes. Chem. Soc. Rev. 2000, 29, 419-427. (d) Sato, O.; Tao, J.; Zhang, Y. Z. Control of magnetic properties through external stimuli. Angew. Chem., Int. Ed. 2007, 46, 2152-2187. (e) Bousseksou, A.; Molnar, G.; Salmon, L.; Nicolazzi, W. Molecular spin crossover phenomenon: recent achievements and prospects. Chem. Soc. Rev. 2011, 40, 3313-3335.

(10) Halcrow, M. A. The spin-states and spin-transitions of mononuclear iron(II) complexes of nitrogen-donor ligands. Polyhedron 2007, 26, 3523-3576.

(11) Bowman, A. C.; Milsmann, C.; Bill, E.; Turner, Z. R.; Lobkovsky, E.; DeBeer, S.; Wieghardt, K.; Chirik, P. J. Synthesis and Electronic Structure Determination of N-Alkyl-Substituted Bis(imino)pyridine Iron Imides Exhibiting Spin Crossover Behavior. J. Am. Chem. Soc. 2011, 133, 17353-17369.

(12) (a) Scepaniak, J. J.; Harris, T. D.; Vogel, C. S.; Sutter, J.; Meyer, K.; Smith, J. M. Spin Crossover in a Four-Coordinate Iron(II) Complex. J. Am. Chem. Soc. 2011, 133, 3824-3827. (b) Mathoniere, C.; Lin, H. J.; Siretanu, D.; Clerac, R.; Smith, J. M. Photoinduced single-molecule magnet properties in a four-coordinate iron(II) spin crossover complex. J. Am. Chem. Soc. 2013, 135, 19083-19086. (c) Lin, H. J.; Siretanu, D.; Dickie, D. A.; Subedi, D.; Scepaniak, J. J.; Mitcov, D.; Clerac, R.; Smith, J. M. Steric and electronic control of the spin state in three-fold symmetric, four-coordinate iron(II) complexes. J. Am. Chem. Soc. 2014, 136, 13326-13332.

(13) Creutz, S. E.; Peters, J. C. Spin-State Tuning at Pseudotetrahedral $\mathrm{d}^{6}$ Ions: Spin Crossover in $\left[\mathrm{BP}_{3}\right] \mathrm{Fe}^{\mathrm{II}}-\mathrm{X}$ Complexes. Inorg. Chem. 2016, 55, 3894-3906.
(14) (a) Travieso-Puente, R.; Broekman, J. O. P.; Chang, M.-C.; Demeshko, S.; Meyer, F.; Otten, E. Spin-Crossover in a Pseudotetrahedral Bis(formazanate) Iron Complex. J. Am. Chem. Soc. 2016, 138, 5503-5506. (b) Milocco, F.; de Vries, F.; Bartels, I. M. A.; Havenith, R. W. A.; Cirera, J.; Demeshko, S.; Meyer, F.; Otten, E. Electronic Control of Spin-Crossover Properties in Four-Coordinate Bis(formazanate) Iron(II) Complexes. J. Am. Chem. Soc. 2020, 142, 20170-20181.

(15) (a) Feltham, H. L. C.; Barltrop, A. S.; Brooker, S. Spin crossover in iron(II) complexes of 3,4,5-tri-substituted-1,2,4-triazole (Rdpt), 3,5-di-substituted-1,2,4-triazolate ( dpt - ), and related ligands. Coord. Chem. Rev. 2017, 344, 26-53. (b) Constable, E. C.; Baum, G.; Bill, E.; Dyson, R.; van Eldik, R.; Fenske, D.; Kaderli, S.; Morris, D.; Neubrand, A.; Neuburger, M.; Smith, D. R.; Wieghardt, K.; Zehnder, M.; Zuberbühler, A. D. Control of Iron(II) Spin States in $2,2^{\prime}: 6^{\prime}, 2^{\prime \prime}$-Terpyridine Complexes through Ligand Substitution. Chem. - Eur. J. 1999, 5, 498-508.

(16) (a) Bacchi, S.; Benaglia, M.; Cozzi, F.; Demartin, F.; Filippini, G.; Gavezzotti, A. X-ray Diffraction and Theoretical Studies for the Quantitative Assessment of Intermolecular Arene-Perfluoroarene Stacking Interactions. Chem. - Eur. J. 2006, 12, 3538-3546. (b) Salonen, L. M.; Ellermann, M.; Diederich, F. Aromatic rings in chemical and biological recognition: energetics and structures. Angew. Chem., Int. Ed. 2011, 50, 4808-4842. (c) Wheeler, S. E. Local Nature of Substituent Effects in Stacking Interactions. J. Am. Chem. Soc. 2011, 133, 10262-10274.

(17) Gütlich, P. Fifty Years of Mössbauer Spectroscopy in Solid State Research - Remarkable Achievements, Future Perspectives. Z. Anorg. Allg. Chem. 2012, 638, 15-43.

(18) Milocco, F.; Demeshko, S.; Meyer, F.; Otten, E. Ferrate(II) complexes with redox-active formazanate ligands. Dalton Trans. 2018, 47, 8817-8823.

(19) Lepori, C.; Guillot, R.; Hannedouche, J. C1-symmetric $\beta$ Diketiminatoiron(II) Complexes for Hydroamination of Primary Alkenylamines. Adv. Synth. Catal. 2019, 361, 714-719.

(20) Weigend, F.; Ahlrichs, R. Balanced basis sets of split valence, triple zeta valence and quadruple zeta valence quality for $\mathrm{H}$ to $\mathrm{Rn}$ : Design and assessment of accuracy. Phys. Chem. Chem. Phys. 2005, 7, 3297-3305.

(21) Becke, A. D. Density-functional exchange-energy approximation with correct asymptotic behavior. Phys. Rev. A 1988, 38, 30983100 .

(22) (a) Staroverov, V. N.; Scuseria, G. E.; Tao, J.; Perdew, J. P. Comparative assessment of a new nonempirical density functional: Molecules and hydrogen-bonded complexes. J. Chem. Phys. 2003, 119, 12129-12137. (b) Tao, J.; Perdew, J. P.; Staroverov, V. N.; Scuseria, G. E. Climbing the Density Functional Ladder: Nonempirical MetaGeneralized Gradient Approximation Designed for Molecules and Solids. Phys. Rev. Lett. 2003, 91, 146401.

(23) Becke, A. D. Density-functional thermochemistry. III. The role of exact exchange. J. Chem. Phys. 1993, 98, 5648-5652.

(24) (a) Harvey, J. N. In Principles and Applications of Density Functional Theory in Inorganic Chemistry I; Springer: Berlin, 2004; pp 151-184. (b) Swart, M.; Gruden, M. Spinning around in TransitionMetal Chemistry. Acc. Chem. Res. 2016, 49, 2690-2697.

(25) These orbital splitting energies are relatively small; spincrossover complexes commonly have significantly larger values for $\Delta$. See for example: Hauser, A. Ligand Field Theoretical Considerations. In Spin Crossover in Transition Metal Compounds I; Gütlich, P., Goodwin, H. A., Eds.; Springer Berlin Heidelberg: Berlin, Heidelberg, 2004, p 49.

(26) (a) Knizia, G. Intrinsic Atomic Orbitals: An Unbiased Bridge between Quantum Theory and Chemical Concepts. J. Chem. Theory Comput. 2013, 9, 4834-4843. (b) Knizia, G.; Klein, J. E. M. N. Electron Flow in Reaction Mechanisms-Revealed from First Principles. Angew. Chem., Int. Ed. 2015, 54, 5518-5522.

(27) Kamphuis, A. J.; Milocco, F.; Koiter, L.; Pescarmona, P. P.; Otten, E. Highly Selective Single-Component Formazanate Ferrate- 
(II) Catalysts for the Conversion of $\mathrm{CO}_{2}$ into Cyclic Carbonates. ChemSusChem 2019, 12, 3635-3641.

(28) Chang, M.-C.; Roewen, P.; Travieso-Puente, R.; Lutz, M.; Otten, E. Formazanate Ligands as Structurally Versatile, Redox-Active Analogues of $\beta$-Diketiminates in Zinc Chemistry. Inorg. Chem. 2015, 54, 379-388.

(29) Chang, M. C.; Otten, E. Synthesis and ligand-based reduction chemistry of boron difluoride complexes with redox-active formazanate ligands. Chem. Commun. 2014, 50, 7431-7433.

(30) (a) Chang, M. C.; Chantzis, A.; Jacquemin, D.; Otten, E. Boron difluorides with formazanate ligands: redox-switchable fluorescent dyes with large stokes shifts. Dalton Trans. 2016, 45, 9477-9484. (b) Chang, M.-C. Formazanate as redox-active, structurally versatile ligand platform: Zinc and boron chemistry. $\mathrm{PhD}$ thesis, University of Groningen, 2016.

(31) Broere, D. L.; Coric, I.; Brosnahan, A.; Holland, P. L. Quantitation of the THF Content in $\mathrm{Fe}\left[\mathrm{N}\left(\mathrm{SiMe}_{3}\right)_{2}\right]_{2} \times \mathrm{xTHF}$. Inorg. Chem. 2017, 56, 3140-3143.

(32) Gilroy, J. B.; Ferguson, M. J.; McDonald, R.; Patrick, B. O.; Hicks, R. G. Formazans as $\beta$-diketiminate analogues. Structural characterization of boratatetrazines and their reduction to borataverdazyl radical anions. Chem. Commun. 2007, 126-128.

(33) Bruker. APEX3, SAINT and SADABS; Bruker AXS Inc.: Madison, WI, 2016.

(34) Sheldrick, G. A short history of SHELX. Acta Crystallogr., Sect. A 2008, 64, 112-122.

(35) Sheldrick, G. Crystal structure refinement with SHELXL. Acta Crystallogr., Sect. C 2015, 71, 3-8. 